Tropical Cyclone Movement and Surrounding Flow Relationships

\author{
by \\ Johnny C.L. Chan \\ and \\ William M. Gray
}

Department of Atmospheric Science

Colorado State University

Fort Collins, Colorado

\title{
Department of Atmospheric Science
}


TROPICAL CYCLONE MOVEMENT AND SURROUNDING FLOW RELATIONSHIPS

\section{By}

Johnny C, L. Chan and William M. Gray

Department of Atmospheric Science

Colorado State University

Fort Collins, Colorado 80523

May, 1982

Atmospheric Science Paper No. 343 


\section{ABSTRACT}

This paper presents results of a comprehensive study of the relationship between the movement of tropical cyclones and the 1 arge-scale circulation which surrounds them. Cyclones have been stratified by direction and speed of movement, 1atitude, intensity change, and size (as determined by the radius of the outermost closed surface isobar) in three ocean basins: the northwest Pacific, the west Atlantic and the Australian-south Pacific region. Twenty-one different stratifications are available in the northwest Pacific, 13 in the west Atlantic, and 6 in the Australian-south Pacific area. Cyclone movement and surrounding flow relationships were studied at different pressure levels and a variety of radii. Pressure-weighted layer-averages were also analyzed in search for such relationships.

Results show an important relationship between surrounding largescale flow and tropical cyclone movement. For all stratifications, the winds in the mid-troposphere $(500-700 \mathrm{mb})$ at 5-7 ${ }^{\circ}$ latitude radius from the cyclone center have the best correlation with cyclone movement. Tropical cyclones in the Northern Hemisphere move about $10-20^{\circ}$ to the left of their surrounding mid-tropospheric flow at 5-7 1atitude radins and those in the Southern Hemisphere move about $10^{\circ}$ to the right. ${ }_{-1}$ is also found that cyclones, in general, move faster by about $1 \mathrm{~m} \mathrm{~s}^{-1}$ than this flow. These general relationships appear to be modified by the vertical shear of the environmental wind, the zonal component of the cyclone velocity, and other characteristics of the cyclone. The mean tropospheric flow (surface to $100 \mathrm{mb}$ ) at 5-7 1 atitude radius also correlates we11 with cyclone movement in most cases. For cyclones embedded in an environment with relatively small vertical wind shear, the mid-tropospheric flow is as good a descriptor of cyclone motion as the mean tropospheric flow. The average wind between the upper (200 mb) and lower ( $900 \mathrm{mb}$ ) troposphere also appears to correlate reasonably well with cyclone movement. 
TABLE OF CONTENTS

Page

1. INTRODUCTION ........................ 1

2. METHODOLOGY AND DATA STRATIFICATIONS . . . . . . . . . . 4

a. Stratifications of the Cyclones . . . . . . . . 4

b. Composite Technique.................. 4

3. RELATIONSHIP BETWEEN THE SURROUNDING FLOW AND THE DIRECTION OF TROPICAL CYCLONE MOVEMENT. . . . . . . . . . . . 14

a. Radial Band Average .................. 16

b. Individual 0ctants. ................. 36

4. RELATIONSHIP BETWEEN THE SURROUNDING FLOW AND THE SPEED OF

TROPICAL CYCLONES .................. 42

a. Radia1 Band Average .................. 42

b. Individual 0ctants. . . . . . . . . . . . . 57

5. SUMMARY AND DISCUSSION ................... 62

ACKNOHLEDGEMENTS. . . . . . . . . . . . . . . . . 65

REFRRENCES. . . . . . . . . . . . . . . . . . . 66 


\section{INTRODUCTION}

It has long been observed that the movement of a tropical cyclone can be described, to a large extent, by the synoptic-scale flow surrounding the cyclone. These observations have led to the steering-flow theory of cyclone movement. It appears that a tropical cyclone can be considered as a point vortex embedded in an air current such that the direction and speed of the center can be approximated by those of its surrounding winds, or equivalently, the pressure or height gradients across the cyclone. The pressure level at which the speed and direction of the surrounding winds best correlate with those of the cyclone is called the steering level.

Based on this idea, a number of tropical cyclone track forecasting schemes have been developed, for example Rieh1 and Shafer (1944), Miller and Moore (1960). Tse (1966) and Renard et al. (1973). For a detailed description of these methods, the reader is referred to the WMO Tropical Cyclone Project Report Number WMO-528 (Wor1d Meteorological Organization, 1979). A1though different forecast schemes employ different steering levels, it is generally accepted that the mid-tropospheric leve1s ( $700 \mathrm{mb}$ and $500 \mathrm{mb}$ ) are the best in predicting tropical cyclone movement. Attempts to use winds and heights at upper tropospheric 1eve1s (see for example, E. Jordan, 1952; Miller, 1958) have not been as suiscesful. No unified conclusion can be drawn from all these schemes on the location (relative to the cyclone center) at which one should measure the surrounding winds or height gradients to get the best description of cyclone movement for all classes of cyclones. This diversity exists because the data samples used in these studies have in 
general not been 1 arge and the variety of cyclone types have not been extensive.

A more comprehensive study on the steering flow problem is therefore necessary in order to determine:

1) which level(s) is/are the best steering level(s);

2) how far from the center of the cyclone the surrounding fllow best correlates with the movement of the cyclone; and

3) if this correlation varies among cyclones in different oceans, with different directions and speeds of movement, at different 1atitudes, of different intensities, intensity changes and sizes, etc.

The study by George and Gray (1976) estab1ished the statistical relationship between the movement of northwest Pacific tropical cyclones and their surrounding winds averaged between $1-7^{\circ}$ latitude radins from the cyclone center. They found that over this broad radial belt, the $500 \mathrm{mb}$ winds have the strongest correlation with the direction of cyclone movement while the $700 \mathrm{mb}$ winds best correlate with cyclone speed. Gray (1977) presented a similar composite analysis of the winds at $1-7^{\circ}$ radius around west Atlantic tropical cyclones. The results were in general agreement with those obtained by George and Gray (1976). Since a large part of the area over which the winds were averaged is very close to the cyclone center, these data included both the cyclone circulation and part of the environmental flow as we11. This radial be1t, therefore, will not provide the best description of the relationships between the movement of a cyclone and its environmental winds. Furthermore, due to the usual lack of upper air data around the cyclone conter, it is typically impossible to apply these results to describo the movement of an individual cyclone. 
The present study is an extension of these two previous analyses. Composite wind data over an area $\left(5^{\circ}-7^{\circ}\right.$ 1atitude radius from the cyclone center) outside the strong inner circulation of the cyclone were correlated with cyclone movement in the west Atlantic, northwest Pacific and Aust:calian-south Pacific regions. More stratifications for both west Atlantic and northwest Pacific cyclones have been included to test the validity of the conclusions in the two previous studies. Data at individual levels as well as mean layer averages were studied and compared for data sets with different characteristics. A combination of the winds in the lower $(900 \mathrm{mb})$ and upper $(200 \mathrm{mb})$ troposphere was also analyzed to test more thoroughiy the idea of using upper and lower tropospheric winds to describe and predict cyclone movement as suggested by Chan et a1. (1980). It is important to test this relationship because satel1ite-derived wind data at lower and upper tropospheric levels have become increasingly available. 


\section{METHODOLOGY AND DATA STRATIFICATIONS}

Becanse of the scarcity of data over the oceans where tropica1 cyclones spend most of their lifetime, the only way to obtain quantitative and representative results is to composite data around cyclones with similar characteristics so that a more even coverage of data can be obtained. Although such a procedure undoubted1y smooths out features particular to individual cyclones, those charaeteristics that are common to all cyclones in the same stratification should be isolated. In addition, random noise from the data will be largely eliminated through the process of averaging. A more detailed description of this compositing philosophy can be found in the papers by Williams and Gray (1973), Frank (1977), Gray (1981) and other Colorado State University tropical cyclone research reports. Corrections for balloon drift and mass-balance were made in the same way as described in these papers and reports.

a. Stratification of the Cyclones

Tropical cyclones with maximum sustained wind speed $\left(V_{\max }\right) \geq 18 \mathrm{~m}$ $s^{-1}$ in the northwest Pacific (time period: 1961-1970), west Atlantic (1961-1974), and Australian-south Pacific (1961-1970) oceans were studied. The cyclones were stratified according to their direction and speed of movement, latitude, intensity, intensity change and size. These stratifications are 1 isted in Tables 1,2 and 3 . b. Compositing Technique

Wind data from rawinsonde stations shown in Fig. 1 (northwest Pacific), 2 (west Atlantic) and 3 (Anstralian-south Pacific region) were composited around cyclones for the stratifications listed in Tables 1-3 
TABLE 1

Description of stratifications of tropical cyclones in the northwest Pacific. All cyflones under study had a maximum sustained wind speed $(V)>18 \mathrm{~m} \mathrm{~s}$. The number of rawinsonde soundings in each group of strat ifications within the $5-7^{\circ}$ latitude radial band is $\sim 1000$.

\section{STRATIFICATION}

By latitude

North Cyclone

South Cyclone

By ispeed

Slow Cycione

Moderate Cyclone

Fast Cyclone

By Direction

Westward Cyclone Northward Cyclone

Eastward Cyclone

By Intensity

Weak Cyclone

Intense Cyclone

Very Intense Cyclone

By Intensity Change

Deepening North Cyclone

Deepening South Cyclone

Filling North Cyclone

Filling South Cyclone

By Size and Intensity Sma11 Tropical Storm Medium Tropical Storm Large Tropical Storm Sma11 Typhoon Medium Typhoon Large Typhoon

\section{DESCRIPTION}

Latitude of cyclone $>20^{\circ} \mathrm{N}$

Latitude of cyclone $\leq 20^{\circ} \mathrm{N}$

Cyclone speed $\left(V_{c}\right) \leq 3 \mathrm{~m} \mathrm{~s}^{-1}$

$4 \mathrm{~ms}^{-1} \leq \mathrm{V}_{\mathrm{c}} \leq 7 \mathrm{~ms}^{-1}$

$v_{c}>7 \mathrm{~ms}^{-1}$

$250^{\circ}<$ Cyclone Direction (CD) $\leq 310^{\circ}$

$310^{\circ}<\mathrm{CD} \leq 350^{\circ}$

$350^{\circ}<C D \leq 60^{\circ}$

$980 \mathrm{mb}<$ Centra1 Pressure (CP) $\leq 1000 \mathrm{mb}$ $950 \mathrm{mb} \leq \mathrm{CP} \leq 980 \mathrm{mb}$

$\mathrm{CP}<950 \mathrm{mb}$

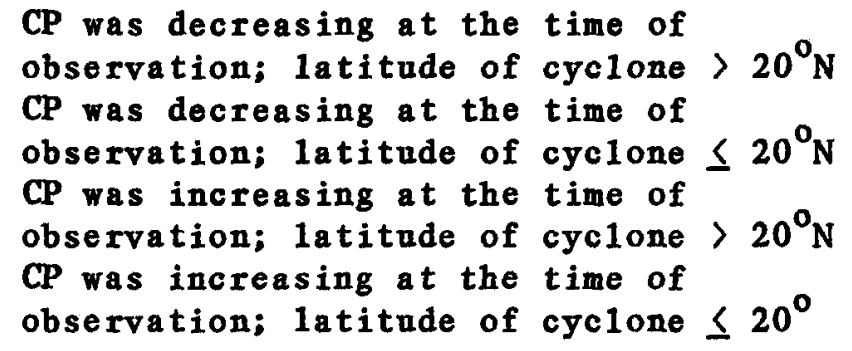

$980<\mathrm{CP}<1000 \mathrm{mb} ; 1^{\circ}<\mathrm{ROCI}^{1}<\underline{3}^{\circ}$ $980 \mathrm{mb}<\mathrm{CP}<1000 \mathrm{mb} ; 4^{0^{2}}<\underline{\mathrm{R} O C I}<\underline{5}^{\circ}$ $980 \mathrm{mb}\left\langle\mathrm{CP}\left\langle 1000 \mathrm{mb} ;\right.\right.$ ROCI $>6^{\circ}$ CP $\leq 980 \mathrm{mb} ; 1^{\%} \leq$ ROCI $\leq 3^{\circ}$ CP $\leq 980 \mathrm{mb} ; 4^{\circ} \leq \mathrm{ROCI} \leq 5^{\circ}$ $\mathrm{CP} \leq 980 \mathrm{mb} ; \mathrm{ROCI} \geq 6^{\circ}$

1 fiocI - radius of outermost closed surface isobar averaged arond the cyclone to the nearest whole degree 1atitude. 
TABLE 2

Same as Table 1 except for tropical cyclones in the west Atlantic. The number of rawinsonde soundings in each group of stratifications within the $5-7^{\circ}$ latitude radial band is $\sim 900$.

STRATIFICATION

By Latitude

Region I Cyclone ${ }^{2}$
Region II Cyclone ${ }^{2}$

\section{DESCRIPTION}

Cyclone location: 1at. $\leq 18^{\circ} \mathrm{N}$, long. $>45^{\circ} \mathrm{W}$ or $1 \mathrm{at} .<\overline{2}^{\circ} \mathrm{N}$, $75^{\circ} \mathrm{W} \leq$ long. $\leq 87^{\circ} \mathrm{W}$.

Cyclone location: $18^{\circ} \mathrm{N}<1$ at. $\leq 35^{\circ} \mathrm{N}$ long. $\geq 45^{\circ} \mathrm{W}$ except those already included in Region $I$.

By Speed

Slow Cyclone

Fast Cyclone

Cyclone speed $<4 \mathrm{~m} \mathrm{~s}-1$
Cyclone speed $>4 \mathrm{~m} \mathrm{~s}-1$

By Direction

Northward Cyclone

Direction of movement: $316^{\circ}-45^{\circ}$

Westward Cyclone

Direction of movement: $225^{\circ}-315^{\circ}$

By Intensity

Hurricane

Maximum sustained wind $\left(V_{\max }\right) \geq 33 \mathrm{~m} \mathrm{~s}^{-1}$

Tropical Storm

$18 \mathrm{~ms}^{-1} \leq V_{\max }<33 \mathrm{~m} \mathrm{~s}^{-1}$

By Size and Intensity

Sma11 Tropica1 Storm $18 \mathrm{~m} \mathrm{~s}^{-1} \leq \mathrm{V}_{\max }<33 \mathrm{~m} \mathrm{~s}^{-1}$; $1^{0} \leq \operatorname{ROCI} \leq 3^{\max }$

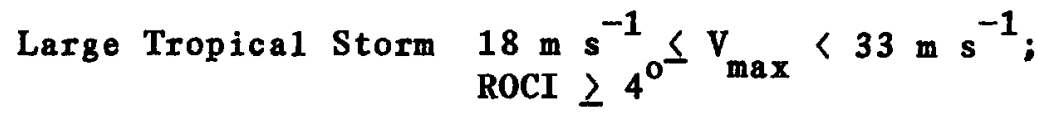

Sma11 Hurricane $\quad V_{\max } \geq 33 \mathrm{~m} \mathrm{~s}^{-1} ; 1^{0} \leq \mathrm{ROCI} \leq 3^{\circ}$

Large Hurricane North Latitude of cyclones > $25^{\circ} \mathrm{N}$

$V_{\max } \geq 33 \mathrm{~m} \mathrm{~s}^{2} ; \operatorname{ROCI} \geq 4^{\circ}$

Large Hurricane South Latitude of cyclones $\leq 25^{\circ} \mathrm{N}$

$\mathrm{V}_{\max } \geq 33 \mathrm{~ms}^{-1}: \operatorname{ROCI} \geq 4^{\circ}$

${ }^{2}$ See Fig. 2 for a more detailed description of the regions. 


\section{TABLE 3}

Same as Tab1e 1 except for tropical cyclones in the Australian-south

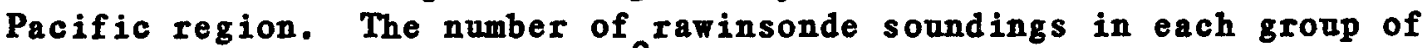
stratifications within the $5-7^{\circ}$ latitude radial band is $\sim 500$.

\section{STRATIFICATION}

DESCRIPTION

By Direction

Eastward Cyclone

CP $\leq 990 \mathrm{mb}$

$40^{\circ} \leq \mathrm{CD} \leq 150^{\circ}$

Westward Cyclone

$\mathrm{CP} \leq 990 \mathrm{mb}$

$210^{\circ} \leq \mathrm{CD} \leq 320^{\circ}$

By Intensity and Region

Al1 Hurricanes

$\mathrm{CP} \leq 990 \mathrm{mb}$

Coral Sea Hurricanes

Longitude east of $136^{\circ} \mathrm{E}$

$\mathrm{CP} \leq 980 \mathrm{mb}$

Coral Sea Tropical Storm Longitude east of $136^{\circ} \mathrm{E}$

$980 \mathrm{mb}<\mathrm{CP}<995 \mathrm{mb}$

West Australian Hurricane Longitude west of $136^{\circ} \mathrm{E}$

CP $<980 \mathrm{mb}$ 


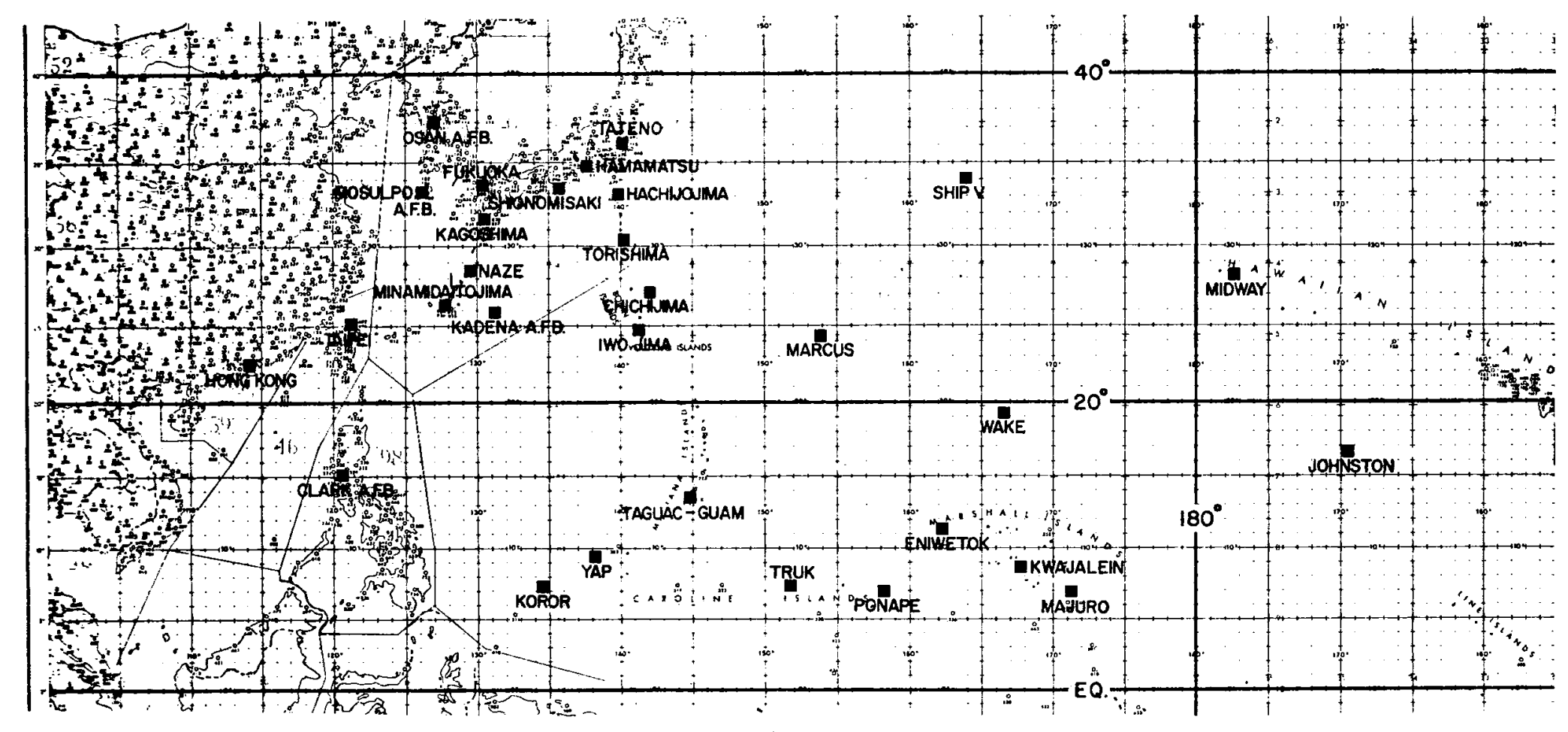

Figure 1. Northwest Pacific rawinsonde stations. 


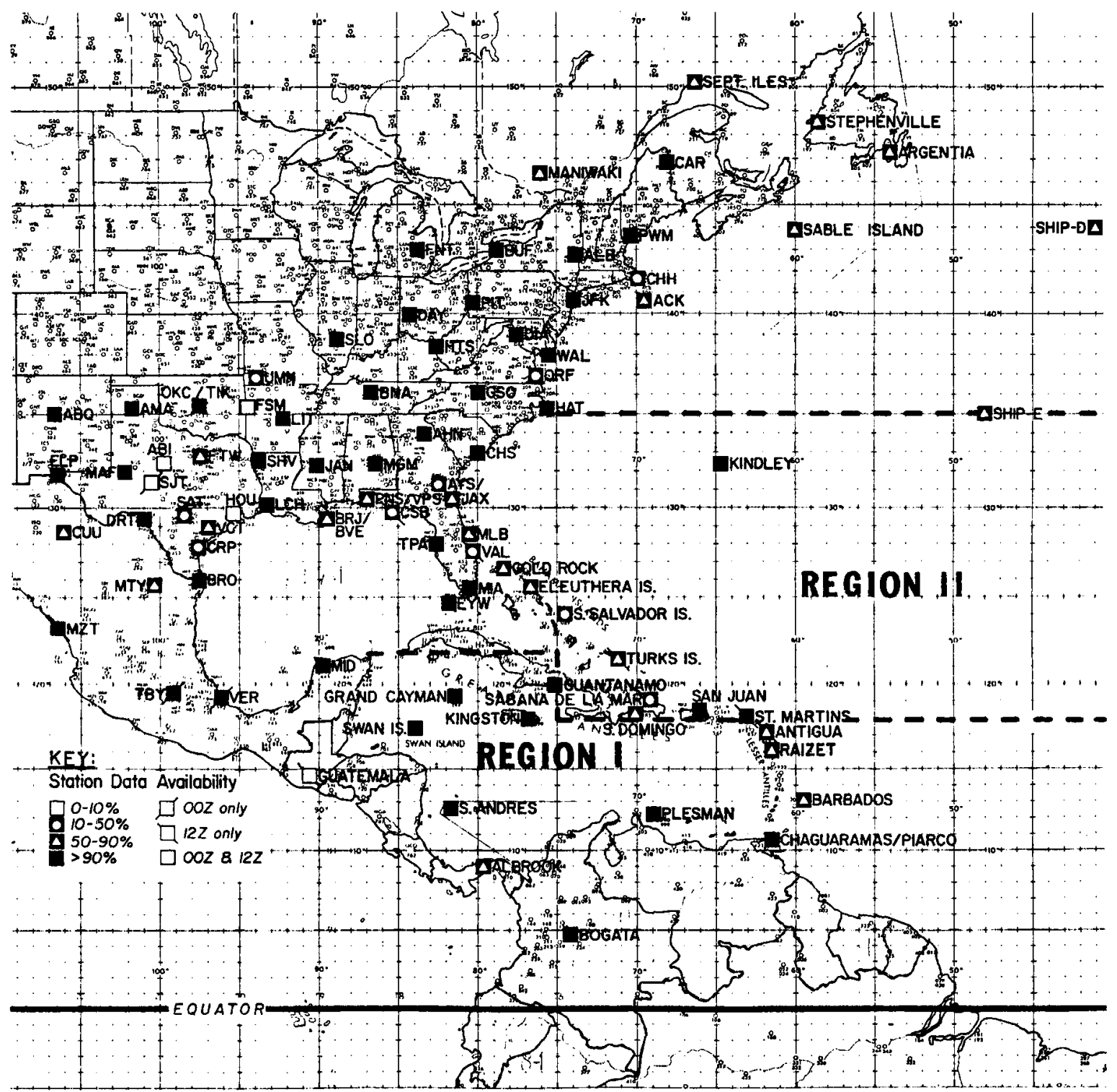

Figure 2. West At1antic rawinsonde stations. 


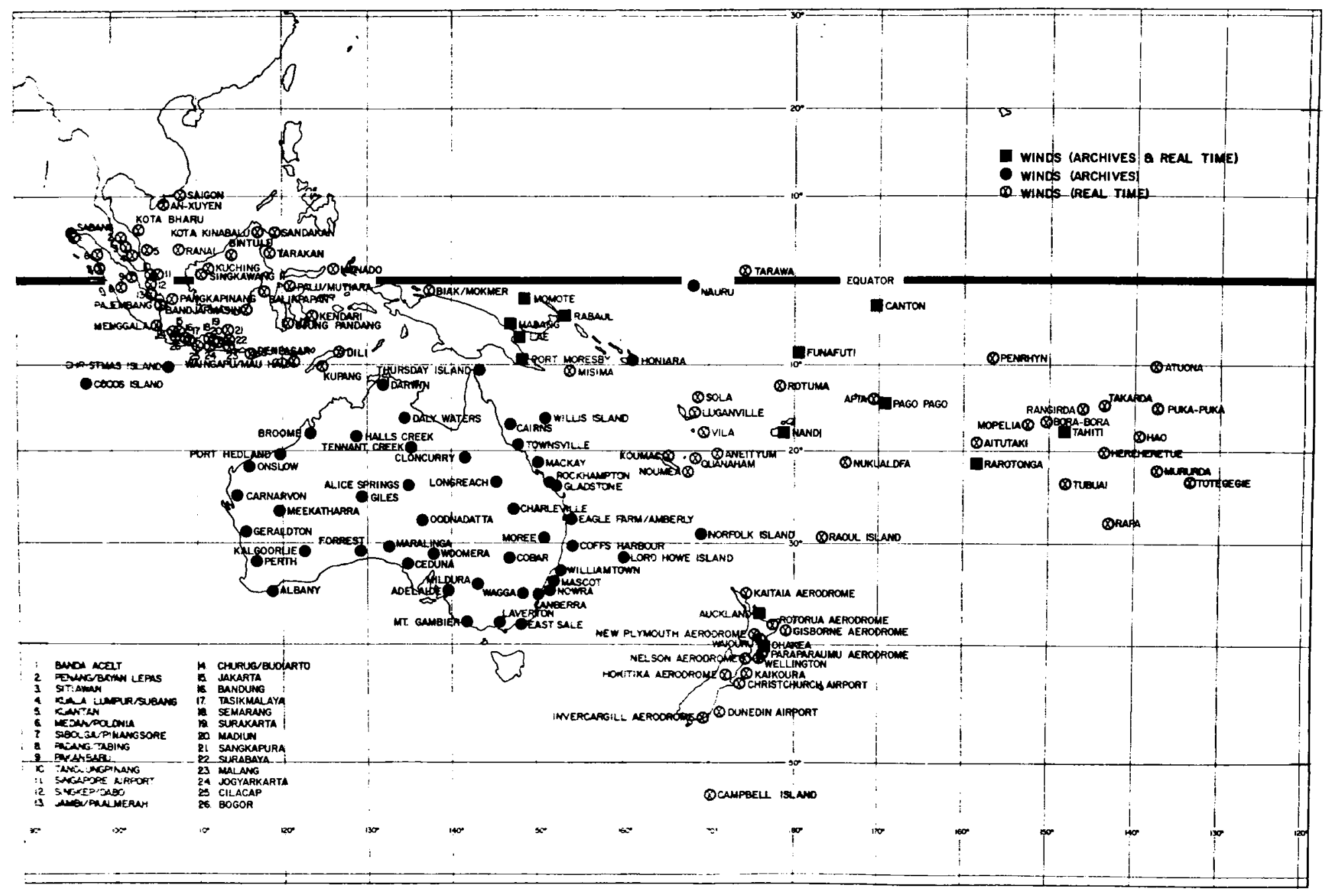

Figure 3. Australian-south Pacific region rawinsonde stations. 
using the circular grid shown in Fig. 4. The center of the grid coincides with the cyclone center. The grid has a radius of $15^{\circ}$ 1atitude ${ }^{3}$ with eight radial bands. Each radial band is divided into eight equal segments or octants and numbered from 1 to 8 in a counterclockwise fashion, with Octant 1 always being in front of the cyclone.

The $\pm 6 h$ (from current position) best-track positions were used to determine the direction and speed of cyclone movement. Each parameter (in this case the wind components) for all soundings falling within any given grid box for a stratification are then averaged. This average value is assigned to the mid-point of the grid box giving 64 values of each parameter at each pressure level.

The wind vectors were resolved in two coordinate systems. The first system involves resolving each wind observation into a parallel component $\left(V_{P}\right)$ along the direction of cyclone movement and a component normal $\left(V_{N}\right)$ to this direction, as shown in Fig. 5. This will be referred to as the ROTated (ROT) system. In order to study the environmental flow relative to the cyclone, a second coordinate system is used in which the speed of the cyclone $V_{c}$ was subtracted out of the parallel wind component $\left(V_{p}\right)$ for each sounding. The composite method was then applied to the difference $V_{P}-V_{C}$ which is labeled as $V_{P M}$ (see Fig. 6). This will be referred to as the MOTROT (for MOTion-ROTated) system. The normal component $V_{N}$ is the same as in the ROT system. See George and Gray (1976) or Chan et al. (1980) for a more detailed description of these two coordinate systems.

3 Hereafter all distances will be referred to in degrees latitude $\left(1^{\circ}\right.$ latitude $=111.1 \mathrm{~km}$ ). 


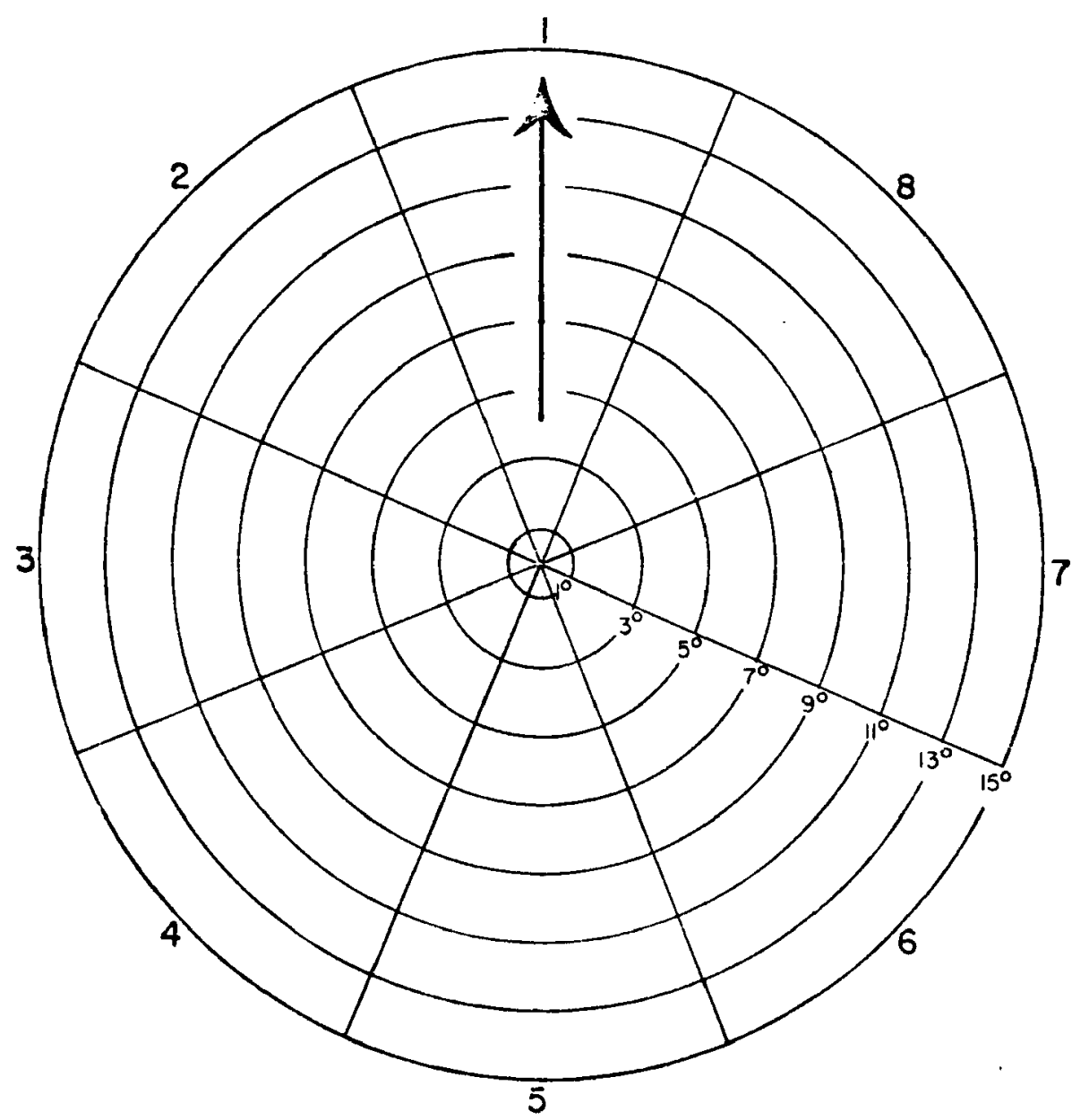

Figure 4. Grid used for compositing rawinsonde data. The arrow points in the direction of storm motion. Outer numbers denote octants. Numbers inside grid indicate distances from the center in degrees 1 atitude. 


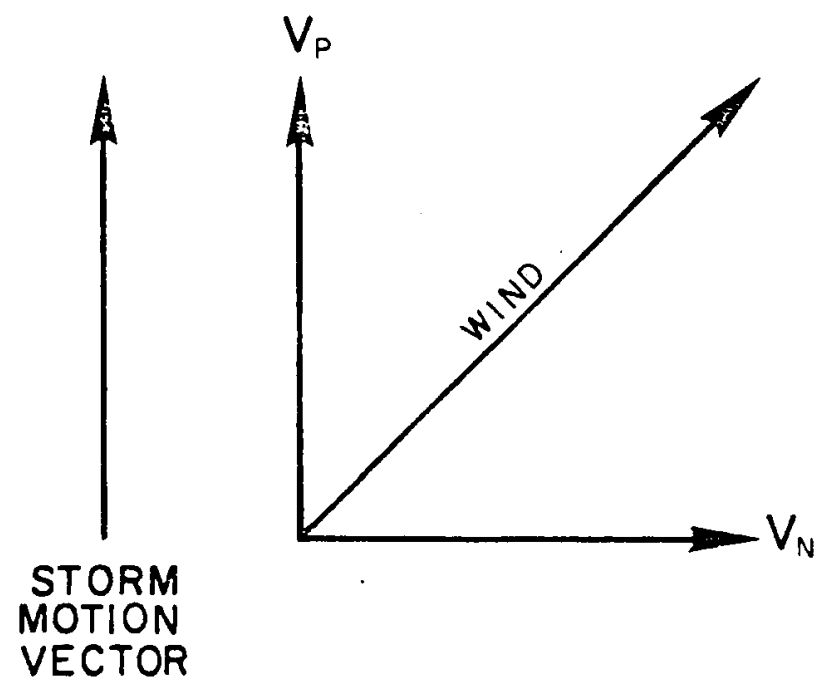

Figure 5. Parallel $\left(V_{P}\right)$ and perpendicular $\left(V_{N}\right)$ component of a wind vector showing their relation to the storm motion vector in the ROT system.

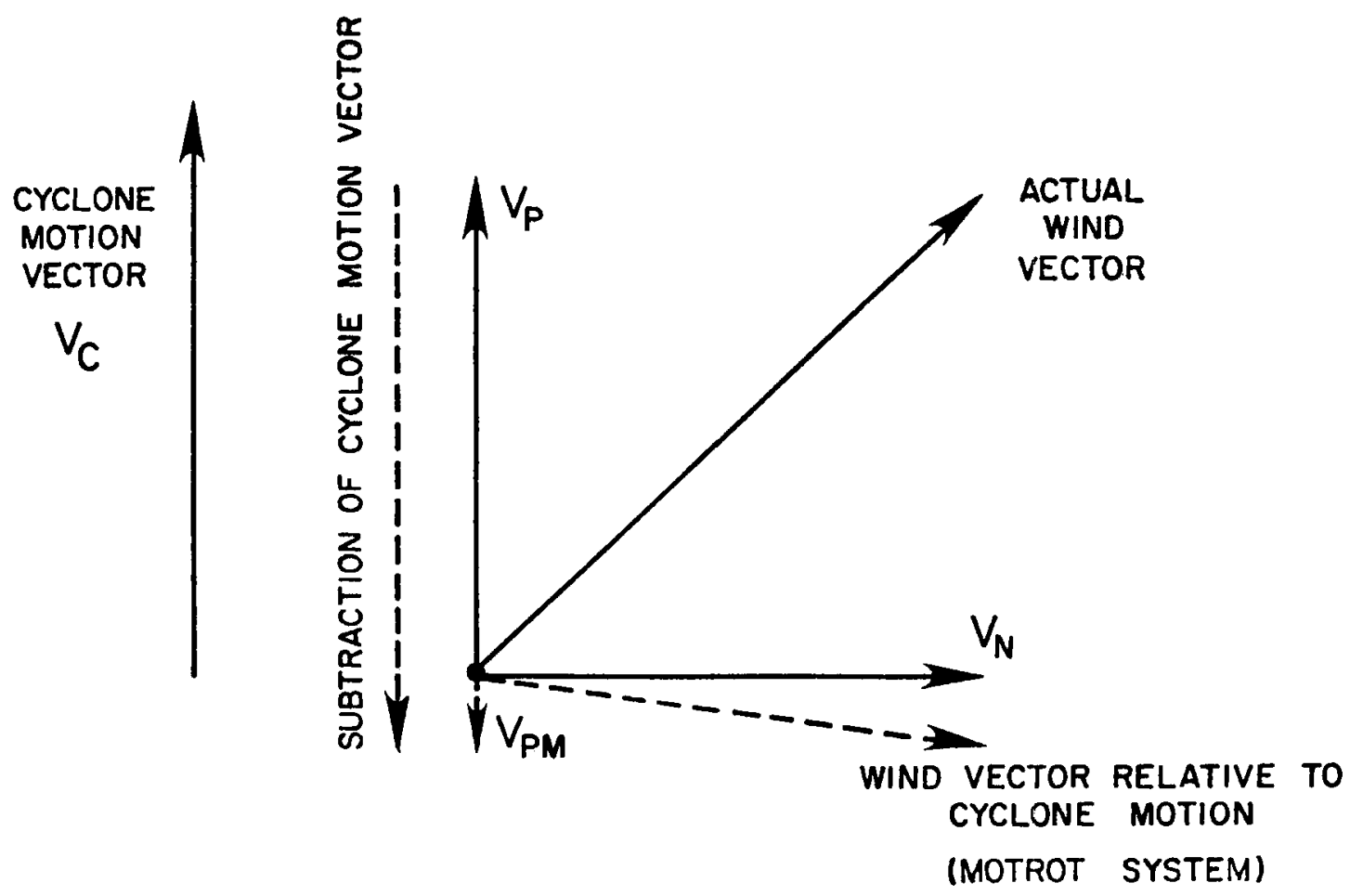

Figure 6. Illustration of the MOTion-ROTated (MOTROT) coordinate system. 
3. RELATIONSHIP BETWEEN THE SURROUNDING FLOW AND THE DIRECTION OF TROPICAL CYCLONE MOVEMENT

A convenient parameter to describe the relationship between the surrounding flow and the direction of movement of tropical cyclones is the difference between the direction of the surrounding wind and that of the cyclone. If the ROT system described in section $2 b$ is used, this Directiona1 Difference (DD) is given by

$$
D= \begin{cases}\arctan \left(V_{N} / V_{P}\right) & V_{P}>0 \\ \arctan \left(V_{N} / V_{P}\right)+180^{\circ} & V_{N}>0, V_{P}<0 \\ \arctan \left(V_{N} / V_{P}\right)-180^{\circ} & V_{N}<0, V_{P}<0\end{cases}
$$

where $V_{N}$ and $V_{P}$ are the components of the composite wind normal and parallel to the direction of cyclone movement. The parameter DD therefore represents the deviation of the composite wind in a particular octant and radial band from the direction of movement of all tropical cyclones in a particular stratification. A positive value of DD means that the cyclone is moving to the left of the composite wind.

The basic assumption in the steering-flow theory is that the vortex and its environmental circulations do not interact. If this is the case, the directional difference at the steering level should be about the same for cyclones with different characteristics. Under this assumption, the steering level can be determined by studying the scatter of the values of DD for data sets in the same ocean at each pressure 1eve1. The scatter $S$ is 


$$
s=\sqrt{\frac{1}{N} \sum_{i=1}^{N}\left(x_{i}-\bar{x}\right)^{2}}
$$

where $N=$ number of data sets

$x_{i}=$ value of the parameter $x$ for data set $i$

$x$ = mean value of the parameter $x$ for all data sets.

In a sense, the scatter is analogous to the standard deviation of a data sample. However, it cannot be interpreted in the same way because the values of $x_{i}$ in this case are not all independent from one another. Furthermore, the $x_{i}$ 's are population means. Nevertheless, the value of $S$ should provide an idea as to the spread of the parameter $x$ among different data sets. The level and radius with the least amount of scatter is then assumed to be the steering level. Mid-tropospheric (700-500 mb) data 5-7 ${ }^{\circ}$ from the cyclone center appear to satisfy this criterion the best. This is not surprising since forecasters have traditionally found these to be the best steering levels.

To make use of this information in practice, reconnaissance flights will have to be made to measure winds at these levels because most of the time, few or no rawinsonde observations are available around a cyclone. Such flights, however, are not routinely flown. A plausible alternative may be to use $200 \mathrm{mb}$ and/or $900 \mathrm{mb}$ winds which can often be derived from satel1ite pictures. An examination of the rawinsonde data shows that the values of DD at these two levels vary significantly between the different stratifications. However, if the $V_{N}$ 's and $V_{P}$ 's at these two levels are averaged and substituted into Eq. (1), the values of DD are quite consistent among data sets. This may prove to be rather useful in areas where only satellite-derived winds are available. 
In some of the track forecast schemes, layer-averaged winds are used to represent the steering current (see, for examp1e, Rieh1 and Burgner, 1950; E. Jordan, 1952; Miller, 1958; Sanders and Burpee, 1968). To see if this idea would yield better results than 'single-level steering', 1ayer-averaged deviations (pressure weighted) have also been computed.

In the following sections, two sets of DD values will be presented: the radial band averages and those at individual octants.

a. Radia1 Band Average

To calculate the radial band average of $D D$, the values of $V_{N}$ and $V_{P}$ in each of the eight octants are averaged to obtain mean $V_{N}$ (or $\bar{V}_{N}$ ) and mean $V_{P}$ (or $\bar{V}_{P}$ ) values. Eq. (1) is then applied using $\bar{v}_{N}$ and $\bar{V}_{P}$ to give the radial band average of $D D$ (or $\overline{D D}$ ). The value $\overline{D D}$ therefore represents the difference between the direction of the mean wind in a particular radial band and that of the cyclone. This was done for all radial bands at each individual pressure leve1. As mentioned above, the smallest scatter in the values of $\overline{D D}$ appears $5-7^{\circ}$ from the cyclone center. Therefore, only data at this radius will be presented.

\section{(i) Variation With Height}

Northwest Pacific. Figure 7 shows a plot of the $5-7^{\circ}$ be1t average winds in the ROT coordinate system (see section $2 b$ ) at different levels for all data sets in the northwest Pacific. These winds were plotted using the values of $\bar{v}_{N}$ and $\bar{v}_{P}$. The direction of cyclone movement is towards the top of the figure. This figure shows that for all the data sets, the cyclone is moving to the left of the direction of the mean wind at all the cyclonio levels (bolow $300 \mathrm{mb}$ ) excopt near the boundary layer (below $900 \mathrm{mb}$ ). The least variability between data sets 

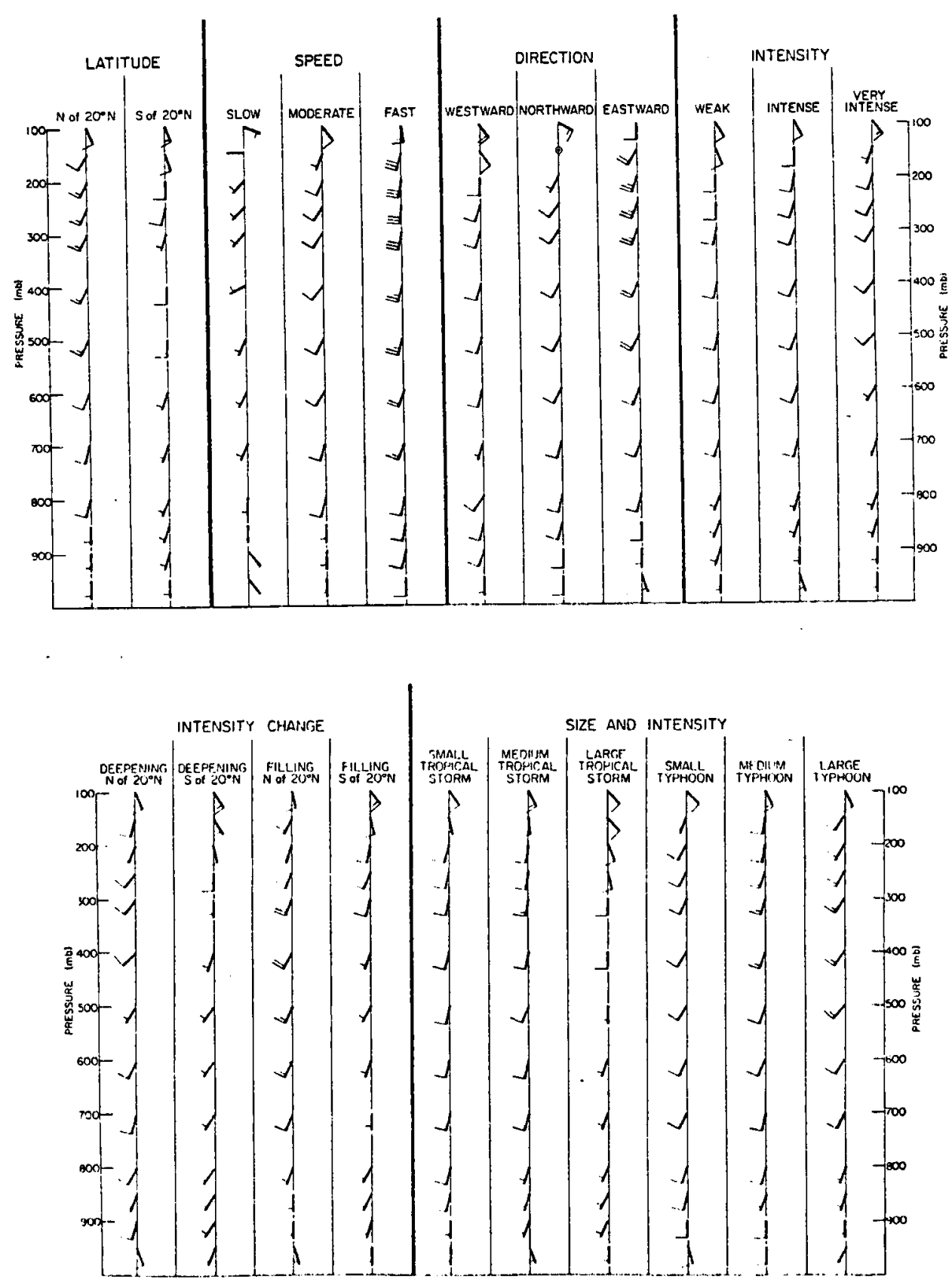

Figure 7. $5-7^{\circ}$ belt average winds in the RoT coordinate system at different pressure levels for all data sets in the northwest Pacific. The direction of cyclone movement is towards the top of the figure. Wind barbs were plotted in the usual meteorplogical convention, one full barb being equivalent to $5 \mathrm{~m} \mathrm{~s}^{-1}$. 
appears to be in the mid-troposphere. More variability exists both at the anticyclonic levels (above $300 \mathrm{mb}$ ) and in the boundary layer.

The actual variations of the be1t average deviation of ( $\overline{\mathrm{DD}}$ ) with height for all the data sets in the northwest Pacific are shown in Fig. 8. A positive number means that the cyclone is moving to the left of the mean wind. It can be seen that for most of the data sets, the values of $\overline{\mathrm{DD}}$ do not vary much throughout a large portion of the troposphere. This suggests that the average flow around most of these cyclones does not have much directional wind shear in the vertical.

Some variations within each category of cyclones can also be seen in Fig. 8. Cyclones at latitudes north of $20^{\circ} \mathrm{N}$ seem to move more to the left of the mean wind than those south of $20^{\circ} \mathrm{N}$. Similar results have a1so been obtained by Brand et a1. (1981). In the speed category, slow-moving cyclones appear to have a much larger variation of $\overline{\mathrm{DD}}$ values in the vertical. Northward-moving cyclones have $\overline{D D}$ values increasing with height while the opposite is true for westward-moving cyclones. As a cyclone increases in intensity it sems to move more to the left of the mean wind. The values of $\overline{D D}$ also appear to increase slightly with the size of a cyclone.

Since not much variability in the values of $\overline{\mathrm{DD}}$ in the vertical exists, winds at a single-level in the mid-troposphere might be nsed to describe the directional movement of a tropical cyclone equally as well as layer-averaged winds. More discussion of this will follow.

West Atlantic. Figure 9 shows the $5-7^{\circ}$ belt average winds in the ROT coordinate system for west Atlantic tropical cyclones. The portion of the atmosphere in which the variability betweon data sets is small seems to be confined only to the mid-troposphere between $700 \mathrm{mb}$ and 500 

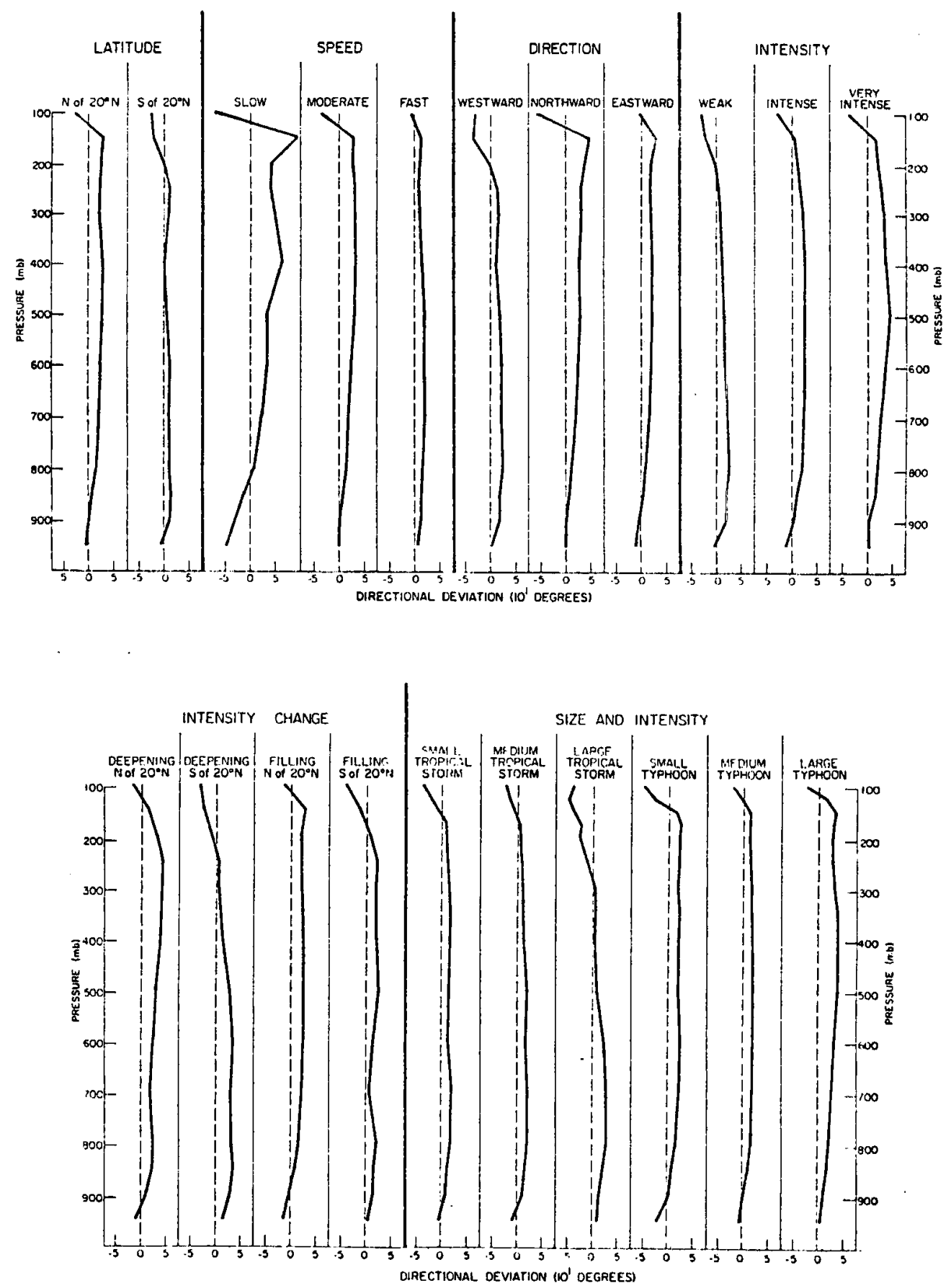

Figure 8. Variation with height of the $5-7^{\circ}$ belt average wind deviation (DD-solid 1ine) for a11 data sets in the northwest Pacific. The zero (dashed) line represents the direction of cyclone movement. A positive yalue means that the cyclone is moving to the left of the $5-7^{\circ}$ belt average wind direction. 


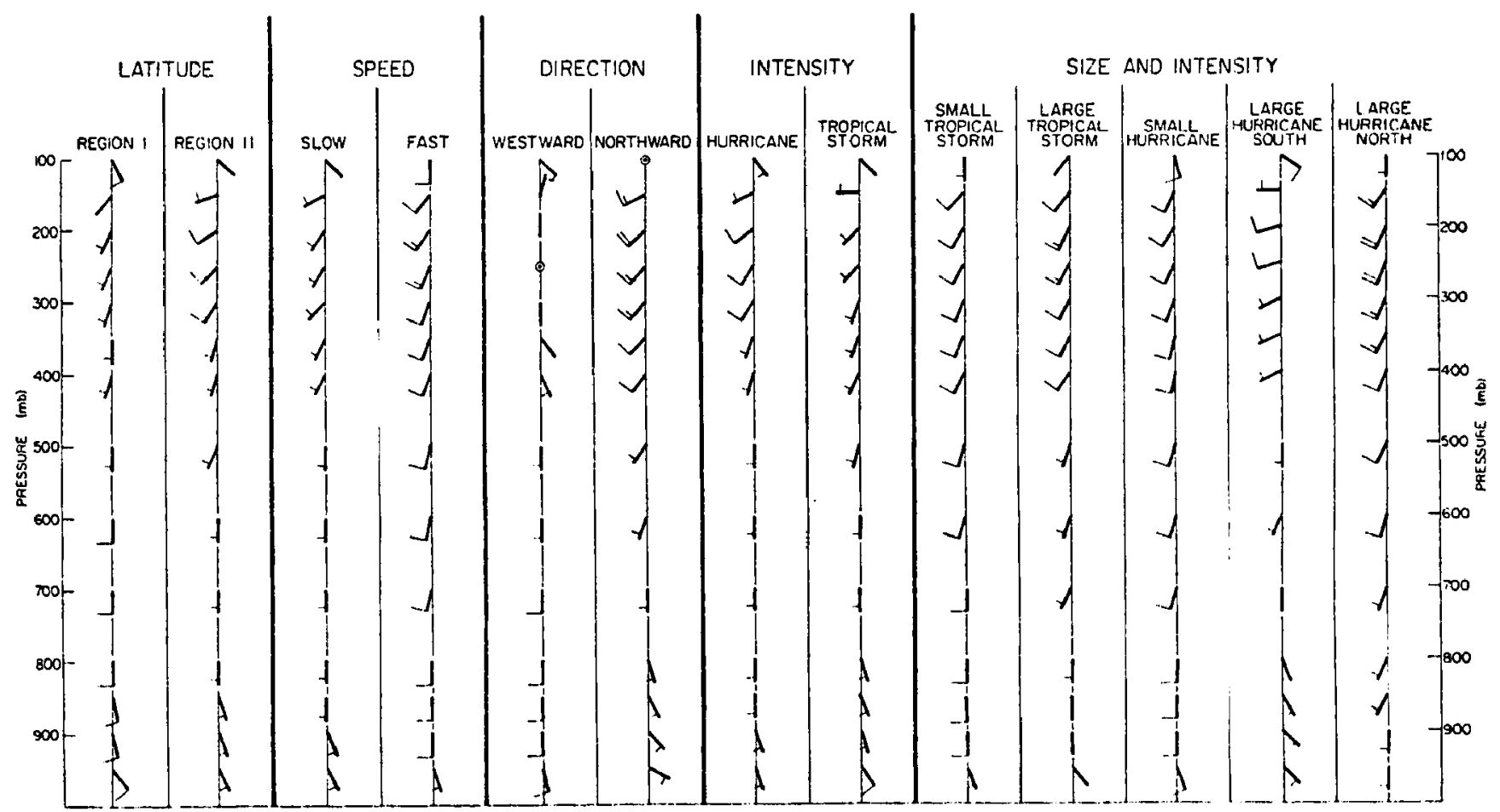

Figure 9. Same as Fig. 7 except for west Atlantic tropical cyc1ones.

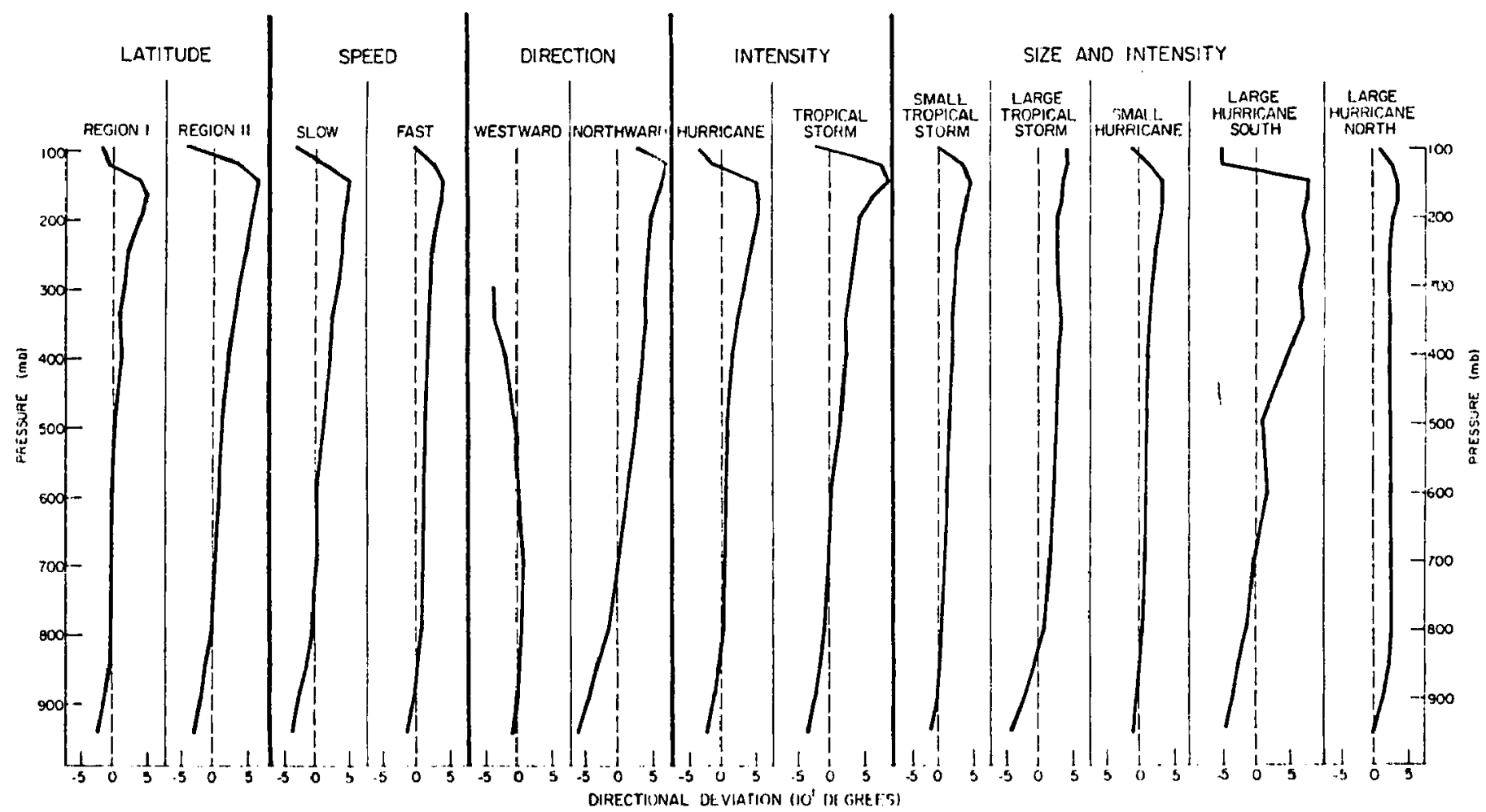

Figure 10. Same as Fig. 8 except for west Atlantic tropical cyclones. 
mb. For each data set, the variation in the vertical is slightly larger when compared with northwest Pacific tropical cyclones. Most cyclones move either in the same direction or to the right of the mean winds below $800 \mathrm{mb}$. In the mid- to upper troposphere, however, west Atlantic cyclones move to the left of the mean wind, as in the northwest Pacific. In the mid-troposphere the winds are, in general, weaker than those in the northwest Pacific and the values of $\overline{D D}$ are also smaller.

These observations are more clearly shown in Fig. 10. There seems to be an increase in the values of $\overline{D D}$ with height from the surface up to $\sim 150 \mathrm{mb}$ for al1 the data sets with the exception of the westwardmoving data set. Westward-moving cyclones appear to move in the same direction or even slightly to the right of the mean wind direction. Values of $\overline{D D}$ above $300 \mathrm{mb}$ for this data set were not plotted because the winds are very weak as shown in Fig. 9 and directional deviations are, therefore, less well defined.

Variations within each category of cyclones can also be seen in Fig. 10. Region I ( south of $18^{\circ} \mathrm{N}$ ) cyclones move less to the left of the mean winds than cyclones in Region II $\left(\sim \operatorname{north}\right.$ of $\left.18^{\circ} \mathrm{N}\right)$. Westward-moving cyclones have different $\overline{D D}$ values than northward-moving cyclones. This is the same as the northwest Pacific except it is more obvious for west Atlantic cyclones. Bigger cyclones tend to move more to the 1eft of the mean wind than smaller cyclones. However, the difference is probably not large enongh to be detected in practice. Therefore, it might be safe to say that the direction of cyclone movement can be described adequately using the 5-7 mean wind irrespective of the size of the cyclone, at least in the midtroposphere. This is true for both west Atlantic and northwest Pacific 
cyclones.

The general increase in the values of $\overline{\mathrm{DD}}$ with height for west Atlantic tropical cyclones suggests that the cyclones are in an environment with a stronger average directional vertical wind shear than northwest Pacific cyclones. This type of shear profile would imply that using layer-averaged steering might be superior to using single-1evel steering. This will be discussed in greater detail later.

Anstralian-south Pacific region. Figure 11 gives the $5-7^{\circ}$ be $1 \mathrm{t}-$ averaged winds in the ROT coordinate system for tropical cyclones in the Australian-south Pacific region. At first glance, the data appear to be very noisy. However, a closer examination shows that for data sets classified under 'intensity and region', the variability among the data sets in the mid- to upper-troposphere is actually very sma11, with the cyclone moving to the right of the mean wind direction above $700 \mathrm{mb}$. This is also the case for eastward-moving cyclones. Westward-moving cyclones, however, move to the left of the mean wind at levels up to 400 mb.

These variations are better illustrated in Fig. 12 which gives the 5-7 $7^{\circ}$ be1t-average deviations $(\overline{\mathrm{DD}})$ at different levels. The values of $\overline{D D}$ genera11y decrease with height, in exact opposite of the west Atlantic. These profiles again demonstrate the existence of an average directional wind shear profile in the vertical. This shear appears to be stronger in the lower troposphere (be1ow $600 \mathrm{mb}$ ).

Another important feature in Fig. 12 is the difference in the $\overline{D D}$ profiles between westward and eastward-moving cyclones. This same type of difference between cyclones moving in different directions also shows up in the two northern hemisphere ocean basins (see Figs, 8 and 10). It 


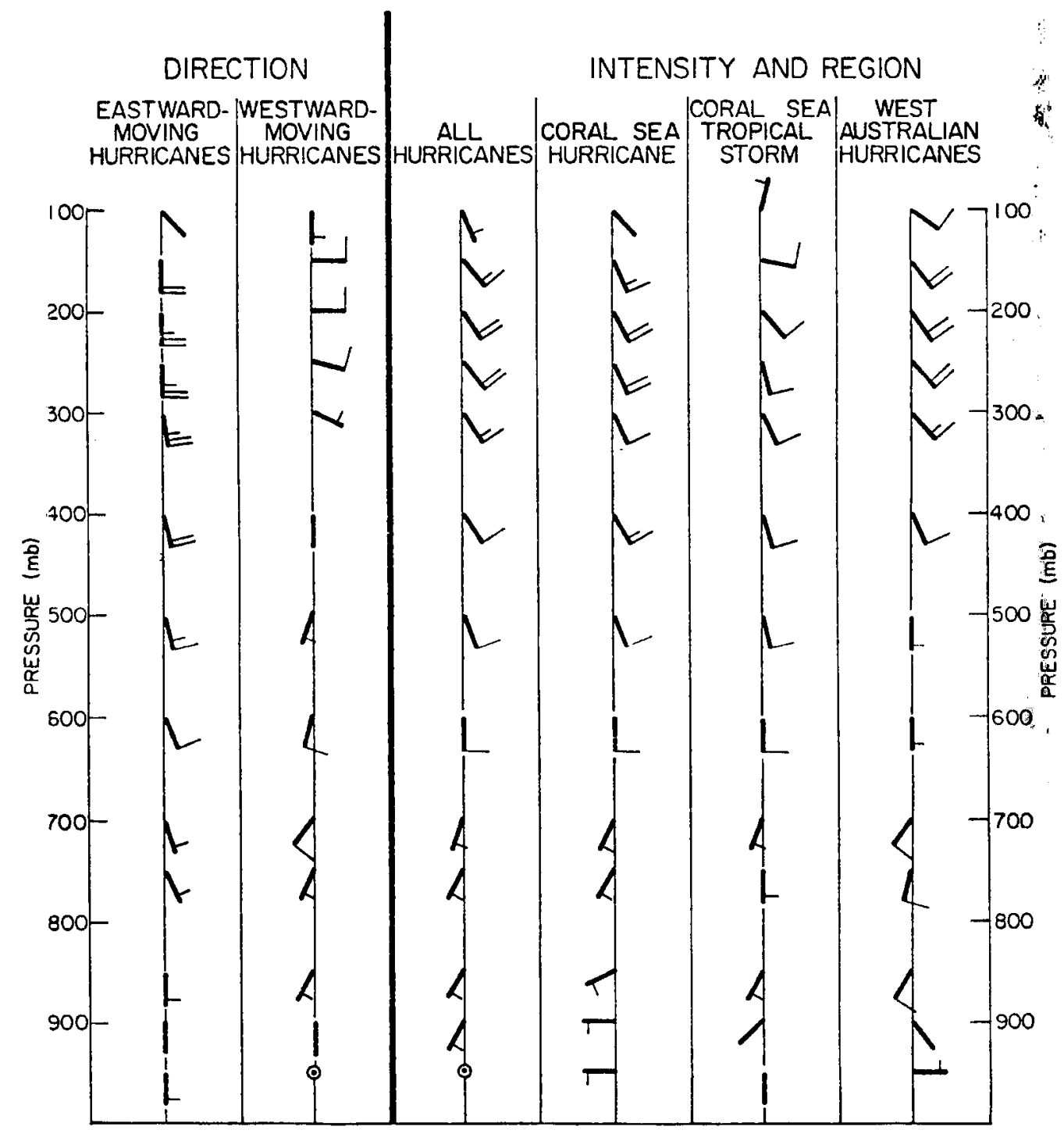

Figure 11. Same as Fig. 7 except for tropical cyclones in the Australian -south Pacific region. 


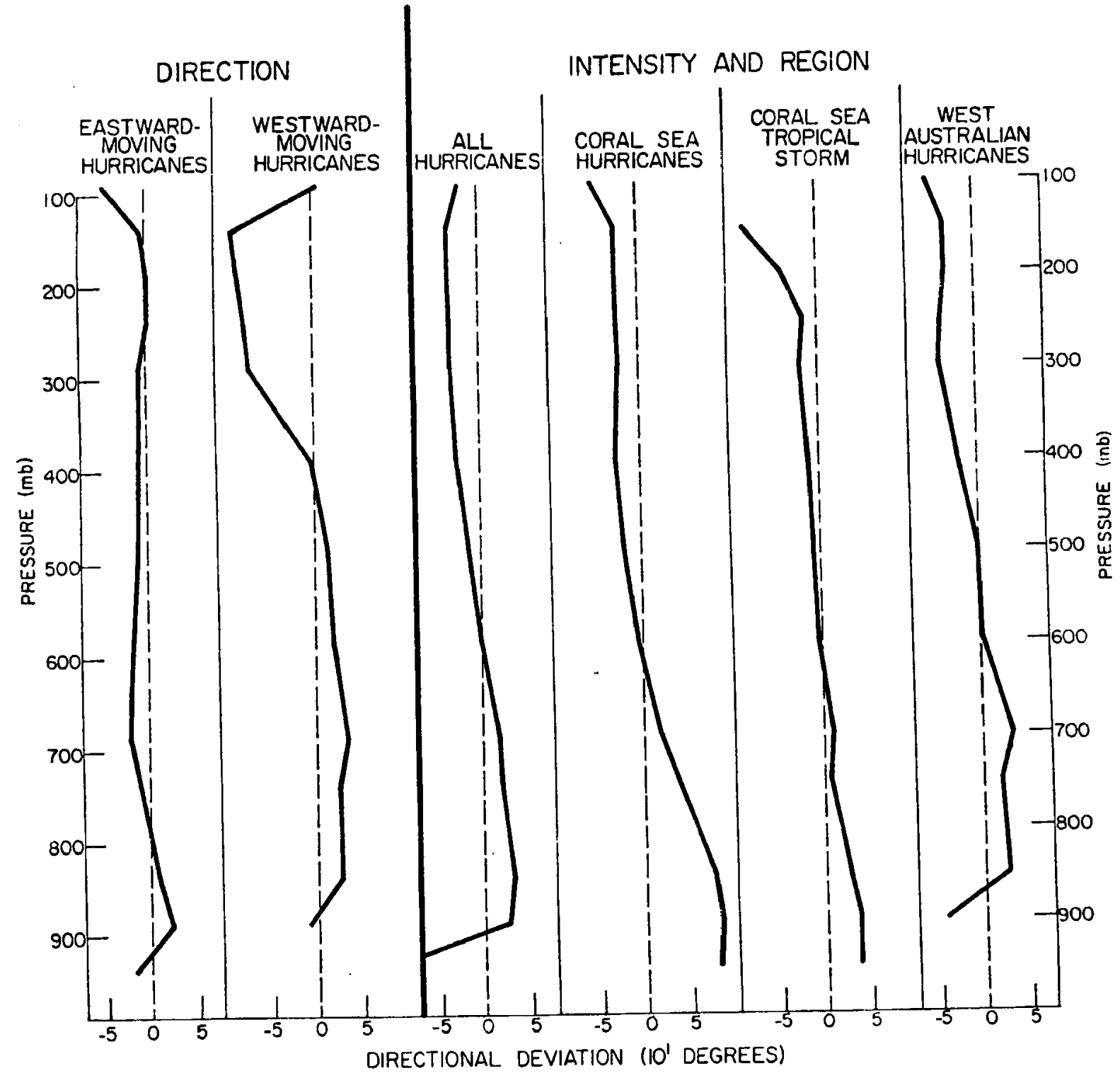

Figure 12. Same as Fig. 8 except for tropical cyclones in the Australian -south Pacific region. 
appears that when directional vertical wind shear is present (as in the west Atlantic and Australian-south Pacific regions), this difference in directiona1 deviations (between cyclones moving in different directions) is more obvious. One must conclude that the deviation of the cyclone direction from that of the mean wind at a given level is related to the zonal and meridional direction of cyclone motion.

Summary. The results in this subsection show that the vertical variation of the deviation of the cyclone direction from the $5-7^{\circ}$ be1t average wind direction for al1 three tropical regions depends on the directional vertical wind shear of the environmental winds. The least variability among data sets in a given ocean basin appears to be in the mid-troposphere. Most cyclones in the Northern Hemisphere move to the left of the $5-7^{\circ}$ be1t average wind (at least in the mid-troposphere) while cyclones in the Southern Hemisphere, in general, move to the right of mid-tropospheric winds at this radius. Such deviations appear to be only slightly modified by latitude, intensity, and size of the cyclone. However, cyclones with different zonal components of motion have large differences in the $\overline{D D}$ values.

\section{(ii) Individual leve1}

As the mid-tropospheric wind data at $5-7^{\circ}$ radius give the least amount of difference in the directional deviations between data sets, these levels will now be more closely examined. The actual values of $\overline{\mathrm{DD}}$ for a11 data sets at 700,600 , and $500 \mathrm{mb}$ and the corresponding scatter are presented.

Northwest Pacific. Table 4 shows the 5-7 $\overline{D D}$ values for northwest Pacific tropical cyclones at 700, 600, and $500 \mathrm{mb}$. A11 cyclones move to the 1 eft of the $5-7^{\circ}$ mean wind by about the same 
TABLE 4

Directional Difference (DD) between the $5^{\circ}-7^{\circ}$ radial band average wind and the direction of cyclone movement for northwest Pacific tropical cyclones. (See text for a description of how the averages and the scatter were calculated.) A positive number indicates the cyclone is moving to the left of the mean wind. Unit: degrees.

STRATIFICATION

By Latitude

North of $20^{\circ} \mathrm{N}$

South of $20^{\circ} \mathrm{N}$

By Speed

S1 ow $\left(1-3 \mathrm{~m} \mathrm{~s}^{-1}\right)$

Moderate (4-7 $\mathrm{p} \mathrm{s}^{-1}$ )

Fast ( $7 \mathrm{~m} \mathrm{~s}^{-1}$ )

By Direction

Westward $\left(250^{\circ}-310^{\circ}\right)$

Northward $\left(310^{\circ}-350^{\circ}\right)$

Eastward $\left(350^{\circ}-60^{\circ}\right)$

By Intensity

Weak $(1000-980 \mathrm{mb})$

Intense $(950-980 \mathrm{mb})$

Very Intense (< $950 \mathrm{mb}$ )

\section{By Intensity Change}

Deepening North of $20^{\circ} \mathrm{N}$

Deepening South of $20 \% \mathrm{~N}$

Filling North of $20 \% \mathrm{~N}$

Filling South of $20^{\circ} \mathrm{N}$

By Size and Intensity

Sma11 Tropical Storm

Medium Tropical Storm

Large Tropical Storm

Sma11 Typhoon

Medium Typhoon

Large Typhoon

Mean

Scatter
$700 \mathrm{mb}$

$600 \mathrm{mb}$

22

10

32

22

17

19
22

23

6.8

9.1 
amount, an indication of the relatively sma11 vertical wind shear in this ocean basin (see Fig. 8). Since such a consistency exists between data sets with widely different characteristics, one might conclude that the steering flow theory appears quite applicable, particularly in the mid-tropospheric leve1s. However, if such a theory is correct, one would expect the value of $\overline{\mathrm{DD}}$ to be near zero. While this is true in a few stratifications, a systematic difference of $\sim 20^{\circ}$ exists between the mean $5-7^{\circ}$ wind direction and the direction of cyclone movement. This suggests that the large-scale flow, though the dominant factor, is not tota11y responsible for the directional movement of the tropical cyclone. Other factors which still need to be identified, must be present to provide such a systematic directional deviation.

West Atlantic. Table 5 gives the values of $\overline{\mathrm{DD}}$ for west Atlantic tropical cyclones. Similar results are found. Cyclones generally move to the left of the $5-7^{\circ}$ mean wind. A few stratifications, however, show different results, particularly the westward-moving tropical cyclones which move s1ight1y to the right of the $500 \mathrm{mb}$ environmental flow.

Australian-south Pacific region. The 5-7 $\overline{D D}$ values for tropical cyclones in the Australian-south Pacific region are shown in Tab1e 6. As discussed earlier, because of the large directional shear of the wind in the lower to mid-troposphere, $\overline{D D}$ values are noisier than those in the other two ocean basins. On the average, cyclones in this region move to the $1 \mathrm{eft}$ of the $5-7^{\circ} 700 \mathrm{mb}$ wind and to the right of the $5-7^{\circ}$ $600 \mathrm{mb}$ and $500 \mathrm{mb}$ wind. This is not true for cyclones having a large zonal component. Westward-moving cyclones move consistently to the left of the $5-7^{\circ}$ mean wind at all three levels while the opposite is true for eastward-moving cyclones. 
TABLE 5

Same as Table 4 except for west Atlantic tropical cyclones.

STRATIFICATION

$700 \mathrm{mb}$

$\underline{600 \mathrm{mb}}$

$\underline{500 \mathrm{mb}}$

By Latitude

Region I (South)

Region II (North)

By Speed

Slow $\left(1-3 \mathrm{~m} \mathrm{~s}^{-1}\right)$
Fast $\left(>3 \mathrm{~m} \mathrm{~s}^{-1}\right)$

By Direction

Northward $\left(316^{\circ}-45^{\circ}\right)$

Westward $\left(225^{\circ}-315^{\circ}\right)$

By Intensity

Hurricane

Tropica1 Storm

By Size and Intensity

Sma11 Tropical Storm

Large Tropical Storm

Sma11 Hurricane

Large Hurricane North

Large Hurricane South

Mean

Scatter

$\begin{array}{rr}-5 & -3 \\ 3 & 7\end{array}$

1

12

$-1 \quad 0$

$9 \quad 11$

11

13

$\begin{array}{lll}0 & 12 & 25\end{array}$

$\begin{array}{lll}5 & -2 & -8\end{array}$

$2 \quad 3 \quad 5$

$\begin{array}{lll}-5 & 0 & 12\end{array}$

$\begin{array}{lll}7 & 10 & 14\end{array}$

162023

$\begin{array}{lll}8 & 8 & 10\end{array}$

$23 \quad 22 \quad 24$

$-3$

5

8.2

8.1

9.3

TABLE 6

Same as Table 4 except for tropical cyclones in the Australian-south Pacific region.

STRATIFICATION

$\underline{700 \mathrm{mb}}$

$\underline{600 \mathrm{mb}}$

$\underline{500 \mathrm{mb}}$

By Direction

Eastward $\left(40^{\circ}-150^{\circ}\right)$
Westward $\left(210^{\circ}-320^{\circ}\right)$

$-24$

$-20$

$-13$

33

19

12

By Intensity and Region

Hurricane

Coral Sea Hurricane

Coral Sea Tropical Storm

West Australian Hurricane

Mean

Scatter
$15-3 \quad-16$

$16-7-22$

$9-5 \quad-9$

32

14

20.8

12.7 
The fact that consistent differences occur for the east and west direction of movement suggests the possible presence of other factors in determining the direction of cyclone movement besides the large-scale mean surrounding flow. Apart from these differences, these results suggest that in exact opposite to the Northern Hemisphere, cyclones in the South Hemisphere generally move to the right (rather than to the 1eft) of the mid-tropospheric flow. This should be expected if the same physical processes are involved.

Summary. Although some variations exist in $\overline{\mathrm{DD}}$ values between different composite data sets, a general consistency is found. Tab1e 7 summarizes the mean values and the corresponding scatter for each of the three ocean basins. It can be seen that cyclones in the northwest Pacific have the smallest variability, a reflection of the small directional vertical wind shear. The direction of movement of west Atlantic cyclones tends to deviate less to the left of the midtropospheric mean wind $\left(\sim 10^{\circ}\right)$ than those in the northwest Pacific $(\sim$ $20^{\circ}$ ). In opposite direction but with similar physical agreement, cyclones in the Southern Hemisphere move to the right of the mean winds at 600 and $500 \mathrm{mb}$. Parts of these results are consistent with those obtained by George and Gray (1976) and Brand et a1. (1981) for the northwest Pacific and those of Gray (1977) for the west Atlantic.

\section{(iii) Level and layer-averages}

Five averages were calculated: surface to $100 \mathrm{mb}$, surface to 300 $\mathrm{mb}$, surface to $500 \mathrm{mb}, 700 \mathrm{mb}$ to $500 \mathrm{mb}$ and the average between the 200 mb and $900 \mathrm{mb}$ levels. The first four layer integrations involve pressure-weighted averages and the last is just the arithmetic mean between the two levels. The radial band averages of the two component 
TABLE 7

Summary of the mean directional differences between cyclone motion and the $5-7^{\circ}$ radial band mean wind averaged for all data sets in each ocean basin. The corresponding scatter within each ocean basin is given in parentheses.

Ocean Basin $700 \mathrm{mb}$

$\underline{600 \mathrm{mb}}$

$500 \mathrm{mb}$

Northwest Pacific

19

22

$(6.8)$

23

West Atlantic

8

11

(8.1)

(9.3)

Austra1ian-

14

(20.8)

\section{$-3$}

(12.7)

$-8$

south Pacific Region

(20.8)

(12.0)

winds $\bar{v}_{N}, \bar{v}_{P}$ were integrated or averaged to get the layer-average $\left\langle\bar{V}_{N}\right\rangle$ and $\left\langle\bar{V}_{P}\right\rangle$. That is, for the pressure-weighted averages,

$$
\left\langle\overline{\mathrm{V}}_{\mathrm{N}}\right\rangle=\frac{\int^{\mathrm{p}_{2}} \overline{\mathrm{V}}_{\mathrm{N}} \mathrm{dp}}{\mathrm{p}_{2}-\mathrm{p}_{1}}
$$

and

$$
\left\langle\bar{v}_{p}\right\rangle=\frac{\int^{p_{2}} \bar{v}_{p} d p}{p_{2}-p_{1}}
$$

where $p_{1}$ and $p_{2}$ are the lower and upper pressure levels of the layer.

The $200 \mathrm{mb}$ and $900 \mathrm{mb}$ arithmetic averages are defined by

$$
\left[\overline{\mathrm{V}}_{\mathrm{N}}\right]=\left[\overline{\mathrm{V}}_{\mathrm{N}}(200 \mathrm{mb})+\overline{\mathrm{V}}_{\mathrm{N}}(900 \mathrm{mb})\right] / 2
$$

and

$$
\left[\bar{v}_{p}\right]=\left[\bar{v}_{p}(200 m b)+\bar{v}_{p}(900 \mathrm{mb})\right] / 2
$$

The layer or leve1-averaged directional deviation is then calculated by 
substituting $\left\langle\overline{\mathrm{V}}_{\mathrm{N}}\right\rangle,\left\langle\overline{\mathrm{V}}_{\mathrm{P}}\right\rangle$ or $\left[\overline{\mathrm{V}}_{\mathrm{N}}\right],\left[\overline{\mathrm{V}}_{\mathrm{P}}\right]$ into Eq. (1).

The reason for choosing the surface to $100 \mathrm{mb}$ layer-average is to test the validity of the suggestion by Sanders and Burpee (1968) that the integrated tropospheric flow is the most applicable 'steering' current. Rieh1 and Burgner (1950) and E. Jordan (1952) used the surface to 300 mb mean flow as their predictor. The surface to 500 mb mean flow is calculated for comparison with the deeper surface to 300 mb mean flow pattern. The results in the previous subsection indicate the importance of mid-tropospheric flow and hence the $700 \mathrm{mb}$ to $500 \mathrm{mb}$ mean flow was a1so ca1culated.

Northwest Pacific. Table 8 shows the layer-averaged values of $\overline{D D}$ for northwest Pacific tropical cyclones. Not much variation exists between the different pressure-weighted averages. This small variation is also reflected in the mean for all the data sets. The scatter among the data sets is about the same for the different layer-averages. The mean flow corresponding to the layer of cyclonic flow (surface to $300 \mathrm{mb}$ or surface to $500 \mathrm{mb}$ ) is slightly better than the other levels. These results again demonstrate the absence of appreciable directional wind shear in the vertical.

The $200 \mathrm{mb}$ and $900 \mathrm{mb}$ average directional deviations also relate in a reasonable way to cyclone motion. With the exception of the large tropical storm data set, the variation between data sets is not large. This suggests that it might be possible to use winds at these levels (derivable from sate11ite pictures) to describe the directional movement of tropical cyclones when other information is not available.

West Atlantic. Table 9 indicates that the directional variability between data sets in the west Atlantic is larger than in the northwest 
TABLE 8

Directional deviations between cyclone direction and direction of leve1or layer-averaged $5^{\circ}-7^{\circ}$ mean winds for different combination of 1 eve1s for northwest Pacific tropical cyclones. See text for a description of how these averages were calculated.

$$
\int_{\text {surface }}^{100 \mathrm{mb}} \int_{\text {surface }}^{300 \mathrm{mb}} \int_{\text {surface }}^{500 \mathrm{mb}} \int_{700 \mathrm{mb}}^{500 \mathrm{mb}} 200 \mathrm{mb}+900 \mathrm{mb}
$$

By Latitude

North of $20^{\circ} \mathrm{N}$

South of $20^{\circ} \mathrm{N}$

19

2

By Speed

S1ow (1-3 m s $\left.\mathrm{s}^{-1}\right)$

Moderate (4-7 y $\mathrm{s}^{-1}$ )

Fast ( $7 \mathrm{~m} \mathrm{~s}^{-1}$ )

By Direction

Westward $\left(250^{\circ}-310^{\circ}\right)$

Northward $\left(310^{\circ}-350^{\circ}\right)$

Eastward $\left(350^{\circ}-60^{\circ}\right)$

9
16

17

29

20

12

27

20

14

19

6

15

8

23

16

3

By Intensity

Weak (1000-980 mb)

Intense (950-980 mb)

Very Intense (<950 mb)

8

16

23

By Intensity Change

Deepening North of $20^{\circ} \mathrm{N}$

Deepening South of $20^{\circ} \mathrm{N}$

Filling North of $20^{\circ} \mathrm{N}$

Filling South of $20^{\circ} \mathrm{N}$

By Size and Intensity

Sma11 Tropica1 Storm

Medium Tropical Storm

Large Tropical Storm

Sma11 Typhoon

Medium Typhoon

Large Typhoon

Mean

15

23

14

19

8

17

17

16

14

20

26

10

14

15

30

23

18

22

16

9

5

13

15

$13 \quad 19$

16

25

34

4

9

13

22

17

30

17

10

13

11

16

19

15

14

26

29

12

18

16

21

Scatter

7.5

5.6

5.2

6.4

8.1

23

13

13

18

19

22

18

31
10

\begin{tabular}{c}
21 \\
8 \\
14 \\
9 \\
\\
8 \\
6 \\
-15 \\
13 \\
7 \\
22 \\
\hline 10 \\
\hline 8.1 \\
\hline
\end{tabular}

6.4


TABLE 9

Same as Table 8 except for west Atlantic tropical cyclones.

$$
\int_{\text {surface }}^{100 \mathrm{mb}} \int_{\text {surface }}^{300 \mathrm{mb}} \int_{\text {surface }}^{500 \mathrm{mb}} \int_{700 \mathrm{mb}}^{500 \mathrm{mb}} \text { Average }
$$

By Latitude

\begin{tabular}{|c|c|c|c|c|c|}
\hline Region I (South) & $\begin{array}{l}-1 \\
16\end{array}$ & $\begin{array}{r}-3 \\
5\end{array}$ & $\begin{array}{l}-7 \\
-4\end{array}$ & $\begin{array}{r}-3 \\
7\end{array}$ & $\begin{array}{l}10 \\
27\end{array}$ \\
\hline \multicolumn{6}{|l|}{ By Speed } \\
\hline S1ow $\left(1-3 \mathrm{~m} \mathrm{~s}_{-1}^{-1}\right)$ & 11 & 3 & -7 & 4 & 16 \\
\hline Fast $\left(>3 \mathrm{~ms}^{-1}\right)$ & 14 & 10 & 7 & 11 & 18 \\
\hline \multicolumn{6}{|l|}{ By Direction } \\
\hline Northward $\left(316^{\circ}-045^{\circ}\right)$ & 27 & 13 & -5 & 13 & 34 \\
\hline Westward $\left(225^{\circ}-315^{\circ}\right)$ & -9 & -5 & -2 & -1 & 1 \\
\hline \multicolumn{6}{|l|}{ By Intensity } \\
\hline Hurricane & 10 & 3 & -3 & 3 & 24 \\
\hline Tropical Storm & 6 & -1 & -8 & 2 & 6 \\
\hline \multicolumn{6}{|l|}{ By Size and Intensity } \\
\hline Sma11 Tropical Storm & 14 & 9 & $\mathbf{5}$ & 10 & 19 \\
\hline Large Tropical Storm & 22 & 18 & 11 & 20 & 19 \\
\hline Sma11 Hurricane & 12 & 8 & 5 & 9 & 16 \\
\hline Large Hurricane North & 22 & 21 & 21 & 23 & 24 \\
\hline Large Hurricane South & 18 & 4 & -12 & 6 & 34 \\
\hline Mean & 13 & 7 & 0 & 8 & 19 \\
\hline Scatter & 9.7 & 7.7 & 9.2 & 7.6 & 9.8 \\
\hline
\end{tabular}


Pacific. The smallest variation appears to be for the surface to $300 \mathrm{mb}$ average and the 700-500 mb average. These results again point to the existence of directional wind shear in the vertical. When integrated over the lower troposphere (surface to $500 \mathrm{mb}$ ), the shear near the boundary layer gives a large variability among data sets. However, when the integration is made up to $300 \mathrm{mb}$ or just in the mid-troposphere $(700-500 \mathrm{mb})$, the effect of the boundary 1ayer is quite smal1. If the upper tropospheric flow is included (surface to $100 \mathrm{mb}$ ), a large variability exists because of the strong shear at the upper levels. Therefore, it appears that in the west Atlantic where directional. wind shear is present in the upper and lower troposphere, either the nidtroposphere or a deep layer corresponding to the cyclonic rotation of the storm is a better predictor of cyclone direction. Because of: the shear between the upper and lower troposphere, the $200 \mathrm{mb}$ and $900 \mathrm{mb}$ average directional deviations do not give as sma11 a variability as their counterparts in the northwest Pacific.

Australian-South Pacific region. Table 10 gives the layer-averaged $\overrightarrow{\mathrm{DD}}$ values for tropical cyclones in the Australian-south Pacific region. The striking result is the consistency among data sets for the surface to $100 \mathrm{mb}$ layer-average. It shows that Australian cyclones move to the right of the $5-7^{\circ}$ mean tropospheric wind. Because of the large directional vertical wind shear, a relatively large variability exists among the different layer-averages for a given data set, with the exception of eastward-moving hurricanes (see Fig. 12). Again, because of the relatively strong directional shear in the vertical, these layer-averages show a larger variability than those in the Northern Hemisphere ocean basins. This is also the case for the $200 \mathrm{mb}$ and 900 
TABLE 10

Same as Table 8 except for tropical cyclones in the Australian-south Pacific region.

$$
\int_{\text {surface }}^{100 \mathrm{mb}} \int_{\text {surface }}^{300 \mathrm{mb}} \int_{\text {surface }}^{500 \mathrm{mb}} \int_{700 \mathrm{mb}}^{500 \mathrm{mb}} 200 \mathrm{mb}+900 \mathrm{mb}
$$

By Direction

$\begin{array}{lrrrrr}\text { Eastward }\left(40^{\circ}-150^{\circ}\right) & -10 & -13 & -14 & -17 & 2 \\ \text { Westward }\left(210^{\circ}-320^{\circ}\right) & -9 & 14 & 22 & 22 & -72 *\end{array}$

By Intensity and Region

\begin{tabular}{lrrrrr} 
Hurricane & -20 & -12 & 3 & -5 & -29 \\
Coral Sea Hurricane & -15 & -7 & 12 & -12 & -15 \\
Coral Sea Tropical Storm & -13 & -2 & 5 & -4 & -23 \\
West Australian Hurricane & -22 & -8 & 10 & 14 & -36 \\
\hline Mean & -15 & -5 & 6 & 0 & -29 \\
Scatter & 5.3 & 10.0 & 12.0 & 15.2 & 24.9 \\
\hline
\end{tabular}

*Such a large directional difference is due to weak $900 \mathrm{mb}$ winds (see Fig. 11). This value is therefore not well defined.

TABLE 11

Same as Table 7 except for leve1- or layer-averaged winds.

Ocean Basin $\int_{\text {surface }}^{100 \mathrm{mb}} \int_{\text {surface }}^{300 \mathrm{mb}} \int_{\text {surface }}^{500 \mathrm{mb}} \int_{700 \mathrm{mb}}^{500 \mathrm{mb}} 200 \mathrm{mb}+900 \mathrm{mb}$

$\begin{array}{llllll}\text { Northwest Pacific } & 15 & 18 & 16 & 21 & 10 \\ & (7.5) & (5.6) & (5.2) & (6.4) & (8.1)\end{array}$

West Atlantic

$\begin{array}{lcccc}13 & 7 & 0 & 8 & 19 \\ (9.7) & (7.7) & (9.2) & (7.6) & (9.8)\end{array}$

Australiansouth Pacific

\begin{tabular}{rcccc}
-15 & -5 & 6 & 0 & -29 \\
$(5.3)$ & $(10.0)$ & $(12.0)$ & $(15.2)$ & $(24.9)$ \\
\hline
\end{tabular}


mb average directional deviation.

Summary. The mean $\overline{D D}$ values for a11 data sets for each leve1- or layer-average for the three ocean basins are shown in Table 11. It shows that the mean tropospheric flow (surface to $100 \mathrm{mb}$ ) gives almost the same results for all the three ocean basins. It seems that the mean tropospheric flow, on the average, would be the best descriptor or predictor for direction of cyclone movement, with cyclones in the Northern Hemisphere moving to the left of this flow by $\sim 15^{\circ}$ and those in the Southern Hemisphere moving to the right by about the same amount. However, it appears that, for individual ocean basins, the best layer depends on the directional vertical shear of the environmental wind in that region. In genera1, the more directional shear there is with height the deeper the steering layer. When 1 ittle directional shear is present, mid-tropospheric and deep layer steering are comparable. The magnitude of vertical directional shear also affects the degree of applicability of winds at $900 \mathrm{mb}$ and $200 \mathrm{mb}$ in describing the directional movement of the cyclone.

b. Individual octants

Although the above results might be used to make good estimates of cyclone motion, such information is usualy not available for individual cyclone situations. Typically, only a few observations are available. Therefore, for practical purposes, it would be useful if only one sector of the cyclone radial band shows similar directional differences as the azimutha1ly-averaged data. To determine if this is possible, the scatter of the DD values at $5-7^{\circ}$ at each octant were calculated. For simplicity only single-level values will be considered. Because beltaverage winds at the mid-tropospheric levels prove to be the 'best' 
steering current, DD values at 700,600 , and 500 mb were investigated. In addition, the $200 \mathrm{mb}$ and $900 \mathrm{mb}$ average winds were investigated. because of their potential applications using sate1lite winds. The analyses indicate that for cyclones in the northwest Pacific and west Atlantic, the octants to the right (octants 6, 7,8 in Fig. 4) of the cyclone at $700 \mathrm{mb}$ have the smallest scatter among data sets. For cyclones in the Australian region, it is the exact opposite - the smallest standard deviations of DD values occur in octants to the left of the cyclone (octants 2, 3, 4 in Fig. 4).

For the mean upper (200 mb) and lower (900 mb) tropospheric winds, the directional difference DD is calculated using Eq. 1 with $\mathrm{V}_{\mathrm{N}}=$ $\left[V_{N}(200)+V_{N}(900)\right] / 2$ and $V_{P}=\left[V_{P}(200)+V_{P}(900)\right] / 2$. As such, it represents the difference between the direction of the mean $200 \mathrm{mb}$ and $900 \mathrm{mb}$ wind in a particular grid box and that of the cyclone. The resulting values, denoted by [DD] are significantly noisier.

Northwest Pacific. Table 12 shows the $700 \mathrm{mb}$ DD values at $5-7^{\circ}$ in octants 6 (right-rear), 7 (right) and 8 (right front) for northwest Pacific tropical cyclones. The average of the three octants is also shown. This is simply the arithmetic average of the DD values in octants 6,7 and 8 . The consistency between data sets is very good, especially for the three-octant average. For the mean $200 \mathrm{mb}$ and $900 \mathrm{mb}$ winds, the best consistency shows up if the [DD] values in octants 6, 7 and 8 are averaged.

West Atlantic. Table 13 gives the same information as Table 12 for west Atlantic cyclones. The consistency among data sets is quite good. The smallest scatter in the DD values occurs in the right octant (7). This is the octant with the strongest wind, and hence, the largest $V_{P}$ 
TABLE 12

Values of DD at $5^{\circ}-7^{\circ}$ for the $700 \mathrm{mb}$ wind and the mean $200 \mathrm{mb}$ and $900 \mathrm{mb}$ wind in the octants indicated. Ocean basin: northwest Pacific.

\begin{tabular}{|c|c|c|c|c|c|}
\hline \multirow[b]{2}{*}{ STRATIFICATION } & \multicolumn{4}{|c|}{$700 \mathrm{mb}$} & \multirow{2}{*}{$\begin{array}{c}200 \mathrm{mb}+900 \mathrm{mb} \\
\text { Ave. } \\
\text { OCTANT } \\
678 \\
\text { Ave. }\end{array}$} \\
\hline & $\begin{array}{c}6 \\
\text { right } \\
\text { rear }\end{array}$ & $\begin{array}{c}\text { OCIANT } \\
7 \\
\text { right }\end{array}$ & $\begin{array}{c}8 \\
\text { right } \\
\text { front }\end{array}$ & $\begin{array}{c}\text { OCTANT } \\
678 \\
\text { Ave. }\end{array}$ & \\
\hline \multicolumn{6}{|l|}{ By Latitude } \\
\hline North of $20^{\circ} \mathrm{N}$ & 25 & 7 & -17 & 5 & 12 \\
\hline South of $20^{\circ} \mathrm{N}$ & 25 & 5 & -42 & -4 & 16 \\
\hline \multicolumn{6}{|l|}{ By Speed } \\
\hline S1 ow $\left(1-3 \mathrm{~m} \mathrm{~s}^{-1}\right)-1$ & 33 & 4 & -28 & 3 & 21 \\
\hline Moderate (4-7_甲 $\left.\mathrm{s}^{-1}\right)$ & 27 & 9 & -16 & 7 & 15 \\
\hline Fast $\left(〉 7 \mathrm{~m} \mathrm{~s}^{-1}\right)$ & 13 & 4 & -14 & 1 & 5 \\
\hline \multicolumn{6}{|l|}{ By Direction } \\
\hline Westward $\left(250^{\circ}-310^{\circ}\right)$ & 28 & 11 & -22 & 6 & 15 \\
\hline Northward $\left(310^{\circ}-350^{\circ}\right)$ & 24 & 10 & -15 & 6 & 12 \\
\hline Eastward $\left(350^{\circ}-60^{\circ}\right)$ & 17 & 1 & -12 & 2 & 6 \\
\hline \multicolumn{6}{|l|}{ By Intensity } \\
\hline Weak $(1000-980 \mathrm{mb})$ & 34 & -2 & -15 & 6 & -2 \\
\hline Intense $(950-980 \mathrm{mb})$ & 30 & 7 & -17 & 7 & 16 \\
\hline Very Intense $(<950 \mathrm{mb})$ & 24 & 13 & -16 & 7 & 13 \\
\hline \multicolumn{6}{|l|}{ By Intensity Change } \\
\hline Deepening North of $20^{\circ} \mathrm{N}$ & 35 & 15 & -9 & 14 & 15 \\
\hline Deepening South of $20^{\circ} \mathrm{N}$ & 32 & 12 & -23 & 7 & 23 \\
\hline Filling North of $20^{\circ} \mathrm{N}$ & 20 & 6 & -14 & 4 & 13 \\
\hline Filling South of $20^{\circ} \mathrm{N}$ & 22 & 15 & -22 & 5 & 36 \\
\hline \multicolumn{6}{|l|}{ By Size and Intensity } \\
\hline Sma11 Tropical Storm & 35 & -4 & -3 & 9 & 2 \\
\hline Medium Tropical Storm & 28 & -2 & -14 & 4 & 5 \\
\hline Large Tropical Storm & 35 & -6 & -27 & 1 & -6 \\
\hline Sma11 Typhoon & 23 & 5 & 6 & 11 & 21 \\
\hline Medium Typhoon & 26 & 4 & -26 & 1 & 8 \\
\hline Large Typhoon & 26 & 5 & -20 & 4 & 14 \\
\hline Mean & 27 & 6 & -17 & 5 & 12 \\
\hline Scatter & 6.0 & 6.0 & 9.7 & 3.9 & 9.2 \\
\hline
\end{tabular}


TABLE 13

Same as Table 12 except for west Atlantic tropical cyclones.

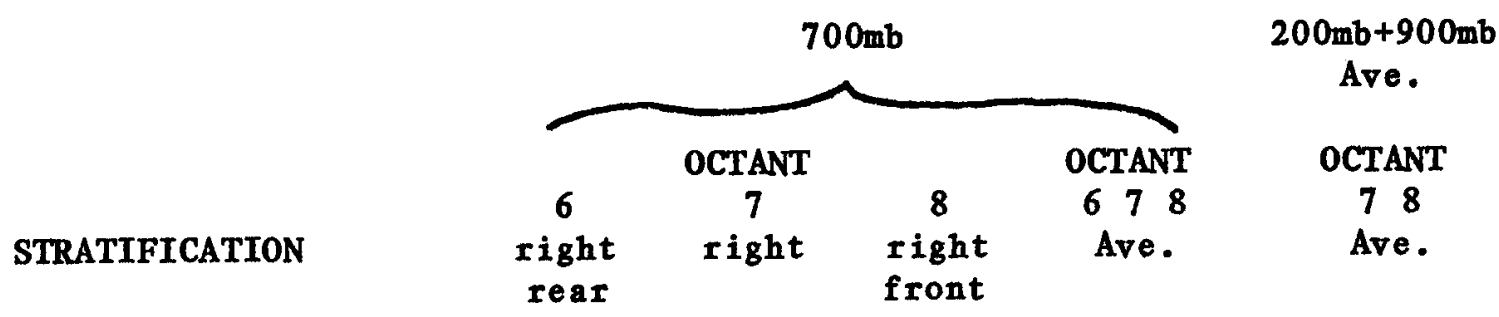

By Latitude

Region I (South)

Region II (North)

By Speed

Slow (1-3 m $\left.\mathrm{s}^{-1}\right)$

Fast ( $3 \mathrm{~m} \mathrm{~s}^{-1}$ )

By Direction

Northward $\left(316^{\circ}-45^{\circ}\right)$

Westward $\left(225^{\circ}-315^{\circ}\right)$

By Intensity

Hurricane

Tropica1 Storm

By Size and Intensity

Sma11 Tropica1 Storm

Large Tropical Storm

Sma11 Hurricane

Large Hurricane North

Large Hurricane South

Mean

24

Scatter

8.4

31

30

22
$-7$

$\begin{array}{ll}-7 & -23\end{array}$

$-4$

1

29

$-1$

$-9$

$-26$

1

$-1$

$-4$

2

$-2 \quad-20$

$-24$

$-9 \quad-10$

0

$-1$

$-15$

$-31$

$-15$

$-30$

$-31$

$-22$

$-1$

30

$-$

3.2

6.8

2.2
28

34

28

23

42

28

26 38

9

32

21

43

9.1 
component. Variations in the normal component of the wind in this octant are small.

For the mean $200 \mathrm{mb}$ and $900 \mathrm{mb}$ wind, the data in octant 6 are very noisy. But if the [DD] values in octants 7 and 8 are averaged, they give a good consistency between data sets.

Australian-south Pacific region. For tropical cyclones in this region, the best steering consistency at $700 \mathrm{mb}$ occurs in octants 2 (front-1eft), 3 (1eft), and 4 (1eft-rear) (see Tab1e 14). For the mean $200 \mathrm{mb}$ and $900 \mathrm{mb}$ wind, the [DD] values are very noisy for most octants. The best consistency is in octant 5 (to the back of the cyclone).

\section{TABLE 14}

Same as Table 12 except for tropical cyclones in the Australian-South Pacific region.

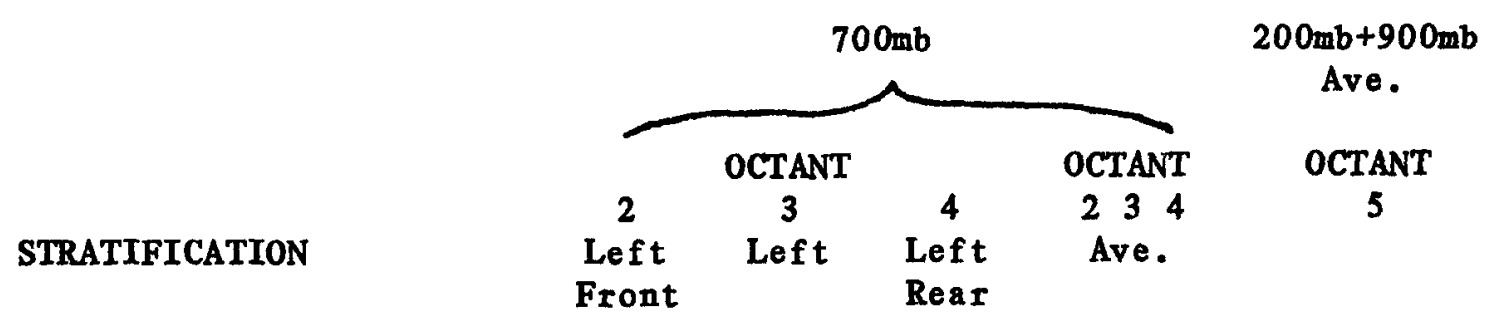

By Direction

$\begin{array}{llllll}\text { Eastward }\left(40^{\circ}-150^{\circ}\right) & 35 & 14 & -25 & 8 & -42 \\ \text { Westward }\left(210^{\circ}-320^{\circ}\right) & 34 & 11 & -25 & 7 & -39\end{array}$

By Intensity and Region

\begin{tabular}{lrrrrr} 
Hurricane & 31 & 16 & -23 & 8 & -45 \\
Cora1 Sea Hurricane & 30 & 0 & -27 & 1 & -37 \\
Cora1 Sea Tropical Storm & 26 & 7 & -28 & 2 & -32 \\
West Australian Hurricane & 32 & 27 & -17 & 14 & -30 \\
\hline Mean & 31 & 13 & -24 & 7 & -38 \\
Scatter & 3.2 & 9.1 & 3.9 & 4.7 & 5.8 \\
\hline
\end{tabular}

Summary. In situations where an estimate of the $5-7^{\circ}$ radial band average wind is not possible, individual octant information appears to 
be almost as useful. The best data appear to be in the region of strongest winds - right-hand-side, or octants 6,7 and 8 , for cyclones in the Northern Hemisphere and left-hand-side, or octants 2, 3 and 4, for cyclones in the Southern Hemisphere.

Although the $200 \mathrm{mb}$ and $900 \mathrm{mb}$ winds tend to be noisier, they do give consistent directional differences around some part of the cyclone. This might prove to be useful in situations where the tracking of clouds is only possible in one sector of the cyclone. 


\section{RELATIONSHIP BETWEEN THE SURROUNDING FLOW AND THE SPEED OF TROPICAL CYCLONES}

In both coordinate systems described in section $2 b$, the winds are resolved into two components, one normal $\left(V_{N}\right)$ and one parallel $\left(V_{p}\right)$ to the direction of cyclone movement. The normal component $V_{N}$ obvious1y does not contribute to the scalar speed of the cyclone. The study of the relation between the surrounding flow and the speed $V_{C}$ of a cyclone therefore reduces to relating the parallel component of the wind $V_{P}$ to $V_{C}$. If the large-scale surrounding flow is the determining factor in cyclone speed, as is the case with cyclone direction, then values of $V_{P}$ relative to cyclone movement should be about the same for different data sets. The MOTROT coordinate system described in section $2 b$ is used for this purpose. That is, for every wind observation, the value of $v_{p}$ relative to the cyclone $\left(V_{P M}\right)$ is calculated from

$$
\mathrm{V}_{\mathbf{P M}}=\mathrm{V}_{\mathbf{P}}-\mathrm{V}_{\mathbf{C}}
$$

See Fig. 6 for an illustration of how this is done. A composite was then made using the individual values of $V_{P}-V_{C}$. The parameter $V_{P M}$ therefore represents the composite relative (to the cyclone) wind component parallel to the cyclone direction. A negative value of $V_{P M}$ means that the cyclone is moving faster than the composite wind. As in the last section, the results will be presented in terms of the radial band average and individaal octant values.

a. Radial Band Average

The radial band average at each pressure level and each radius is the average of the $V_{P M}$ for all eight octants in that radial band, denoted by $\overline{\mathrm{V}}_{\mathrm{PM}}$. To find the 'best' steering level and radius for 
cyclone speed, the scatter of $\vec{V}_{P M}$ for data sets at various levels and radii were calculated in the same way as described in the last section. Again, the $5-7^{\circ}$ radial band at the three mid-tropospheric levels (700, 600 and $500 \mathrm{mb}$ ) have the sma1lest scatter among data sets for al1 three ocean basins. Following the procedure used in section 3 , the variation of $5-7^{\circ} \bar{v}_{P M}$ with height will be presented, followed by individual levels and then 1eve1- or 1ayer-averaged winds.

\section{(i) Variation with height}

Northwest Pacific. Figure 13 shows the vertical profile of $\bar{v}_{P M}$ at $5-7^{\circ}$ for northwest Pacific tropical cyclones. Not much variation in the vertical exists for most data sets except for the data set north of $20^{\circ} \mathrm{N}$, the fast-moving, eastward-moving, filling north of $20^{\circ} \mathrm{N}$ and 1 arge typhoon data sets. This means that with the exception of these five stratifications, the other cyclones are generally embedded in an environment with relatively small vertical speed shear. The variation among different data sets, if those five stratifications are excluded, is very sma11. These data sets all have a strong northward and/or eastward component of motion. Therefore, it appears that the zonal and meridional movement of a cyclone have some effect on the cyclone speed relative to the surrounding winds. However, for a11 data sets, the values of $\overline{\mathrm{V}}_{\mathrm{PM}}$ are negative below $\sim 600 \mathrm{mb}$. This means that tropical cyclones in the northwest Pacific generally move faster than their surrounding mean $5-7^{\circ}$ winds in the lower to mid-troposphere.

West Atlantic. The vertical profiles of $5-7^{\circ} \overline{\mathrm{V}}_{\mathrm{PM}}$ values for west Atlantic tropical cyclones are shown in Fig. 14. The variation with height for most data sets is not very large. Noticeable exceptions are westward- and northward-moving cyclones, large tropical storms and large 

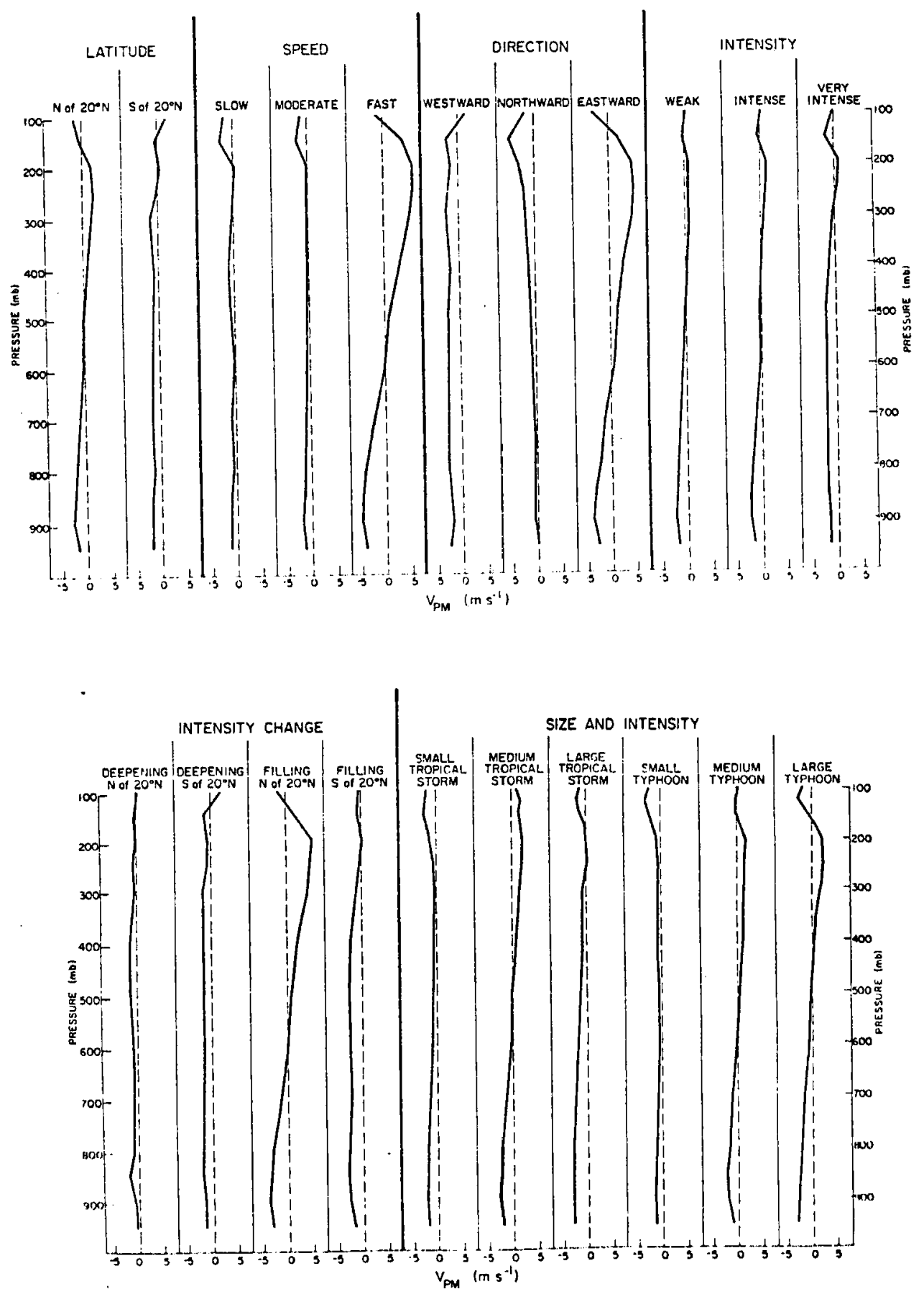

Figure 13. Variation with height of the $5-7^{\circ}$ belt average relative component of the wind parallel to cyclone direction $\bar{V}_{\mathrm{PM}}$ for northwest Pacific tropical cyclones (solid line). The zero (dashed) line represents the cyclone speed. A negative value of $V_{p M}$ means that the cyclone is moving faster than the 5-7 surrounding wind. 


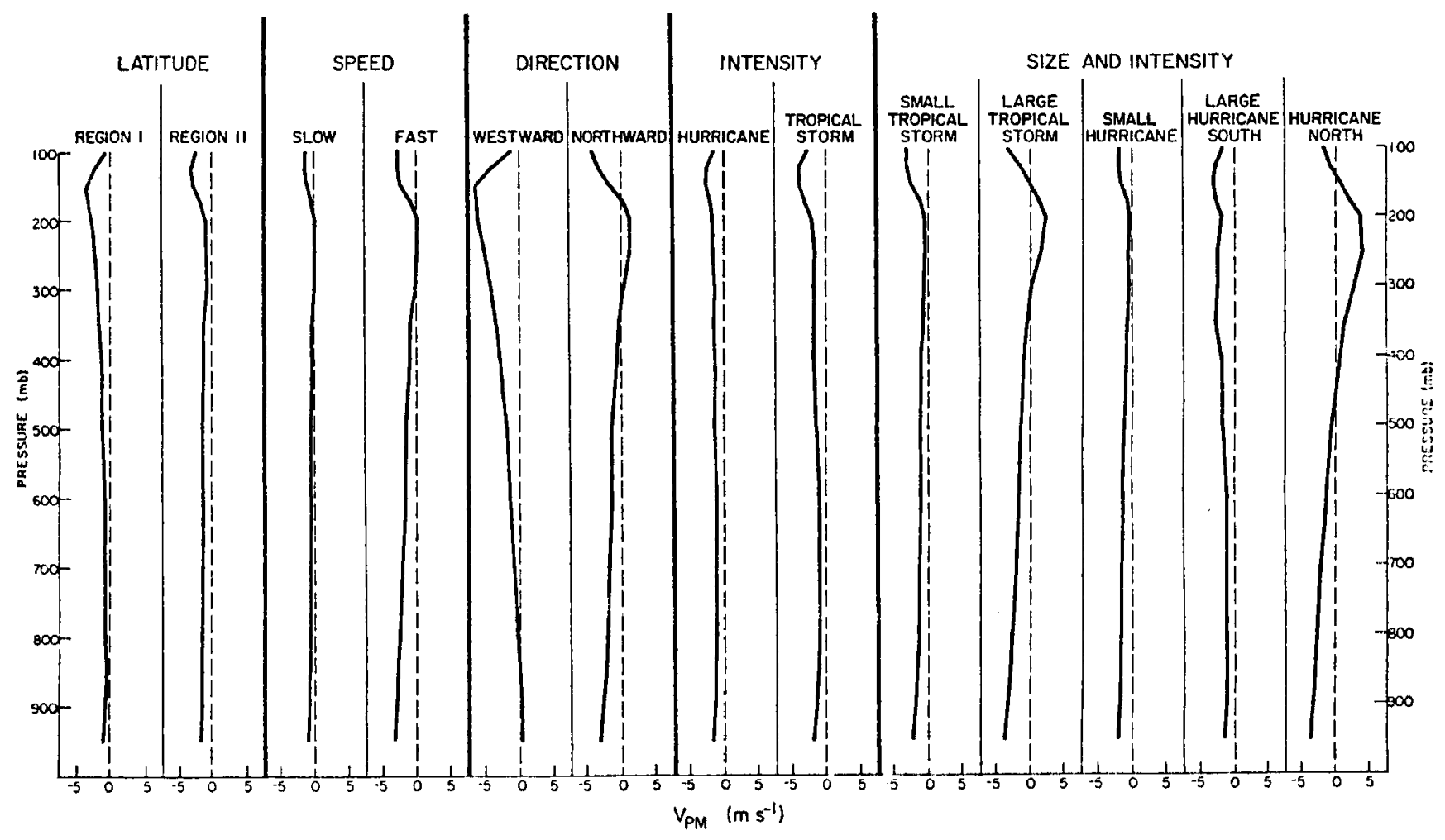

Figure 14. Same as Fig. 13 except for west Atlantic tropical cyclones. 
hurricanes north of $25^{\circ} \mathrm{N}$. Again, a11 cyclones move faster than the lower and mid-tropospheric winds $\left(\bar{\nabla}_{P M}<0\right)$. Between data sets, very 1ittle difference between the values of $\vec{V}_{P M}$ can be noticed, especially in the mid-troposphere. It is also of interest to note that similar relationships between the $5-7^{\circ}$ wind speed and the cyclone speed holds for cyclones of different sizes in both the northwest Pacific and the west Atlantic. It therefore appears that despite the difference in the sizes of cyclones, the $5-7^{\circ}$ surrounding flow can be used to describe cyclone movement satisfactorily.

Australian-south Pacific region. Figure 15 shows the vertical profiles of $5-7^{\circ} \quad \bar{v}_{P M}$ values for tropical cyclones in this region. Considerable variation of $\bar{V}_{P M}$ with height exists for most data sets, indicating a large speed shear in the vertical. Similar to those in the Northern Hemisphere, al1 cyclones move faster than the mean wind in the lower troposphere (below $600 \mathrm{mb}$ ). Although strong shear is present, the values of $\bar{V}_{P M}$ in the mid-troposphere are about the same among different data sets.

Summary. The vertical profiles of $\overline{\mathrm{V}}_{\mathrm{PM}}$ at $5-7^{\circ}$ do not show much variation among cyclones in the three ocean basins, when compared to the vertical profiles of directional deviations. Exceptions arise when the cyclone is in an environment with strong vertical speed shear. However, all the data sets indicate that cyclones tend to move faster than the 5-7 $7^{\circ}$ mean wind at the mid-troposphere. This is consistent with the results obtained by George and Gray (1976) and Gray (1977). If the steering flow is totally responsible for the movement of a cyclone, one would expect $\bar{V}_{\mathrm{PM}}$ to be near zero. The fact that $\overline{\mathrm{V}}_{\mathrm{PM}}$ is a1ways negative, at least in the mid-troposphere, points out the existence of 


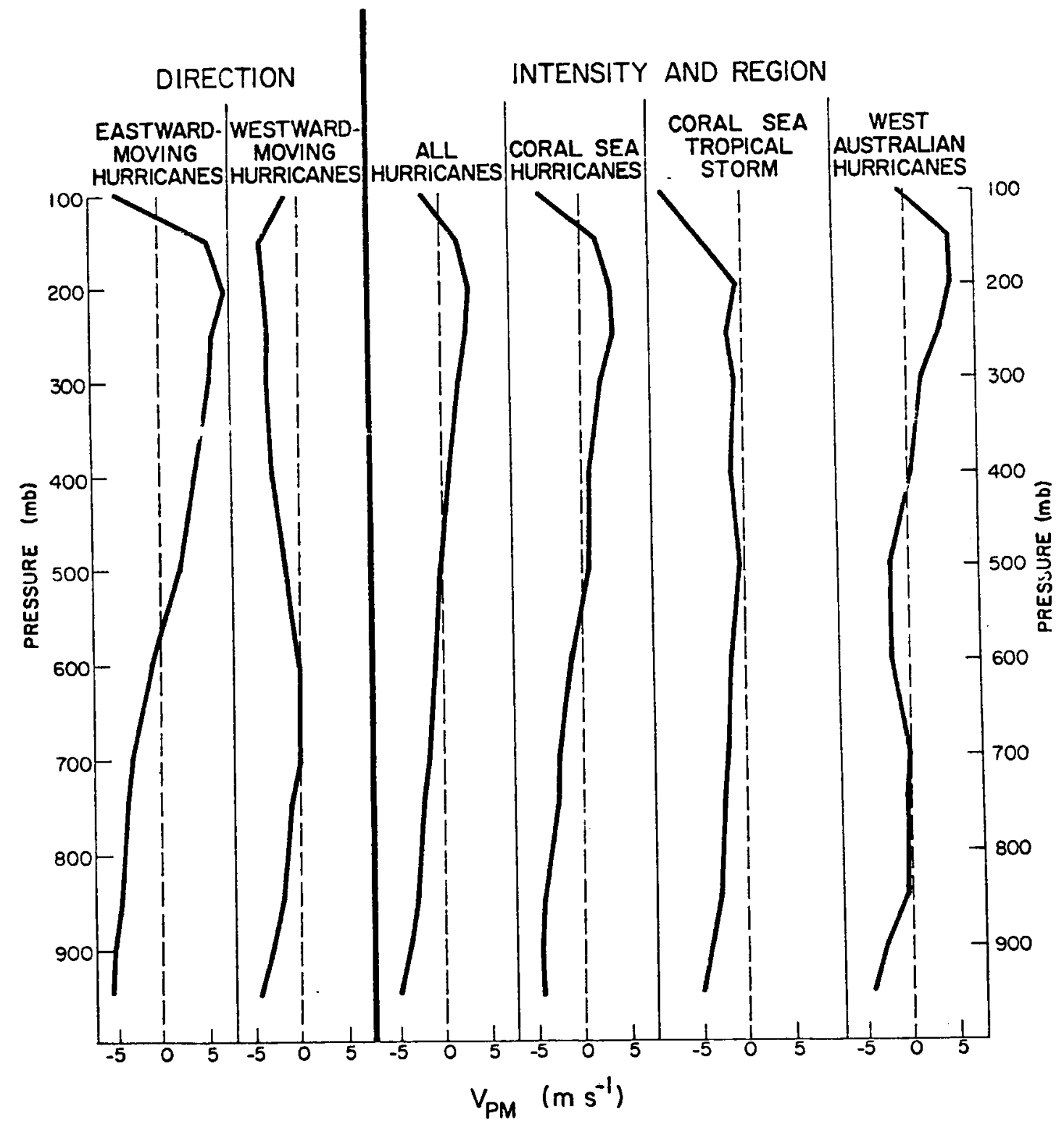

Figure 15. Same as Fig. 13 except for Australian-south Pacific region tropical cyclones. 
other factors in the determination of the speed of a cyclone.

\section{(ii) Individual leve1s}

The results in the last subsection suggest that mid-tropospheric data correlate best with cyclone speed. To quantify these results, the values of $\bar{V}_{P M}$ at 700,600 and $500 \mathrm{mb}$ and the corresponding standard deviations between data sets are specifically portrayed.

Northwest Pacific. Table 15 gives the values of $\bar{V}_{P M}$ at $5-7^{\circ}$ for three mid-tropospheric levels for northwest Pacific tropical cyclones. It can be seen that the $\vec{V}_{P M}$ values at $700 \mathrm{mb}$ have the least spread among data sets. Notice that all data sets show a negative $\overline{\mathrm{V}}_{\mathrm{PM}}$, meaning that a tropical cyclone travels faster than its $6^{\circ}$ mean $700 \mathrm{mb}$ wind. Similar observations can be made about the 600 and $500 \mathrm{mb}$ data with the exception of eastward-moving, fast and filling north of $20^{\circ} \mathrm{N}$ cyclones. This again points to the importance of the zonal and meridional directions of cyclone motion.

West Atlantic. The values of $5-7^{\circ} \bar{v}_{P M}$ at 700,600 and $500 \mathrm{mb}$ for west Atlantic tropical cyclones are shown in Table 16. Very 1ittle scatter exists in the data sets for all three mid-tropospheric levels, as evidenced from the standard deviations. The results also show that a cyclone travels faster than its surrounding $6^{\circ}$ mid-tropospheric winds.

Anstralian-south Pacific region. Table 17 presents the midtropospheric $5-7^{\circ}$ values of $\bar{V}_{P M}$ for tropical cyclones in the Australian-south Pacific region. As mentioned in the 1ast sub-section, although large vertical speed shear exists in this region, the values of $\bar{V}_{P M}$ do not differ very much between data sets. Again, cyclones travol $\sim 1 \mathrm{~m} \mathrm{~s}^{-1}$ faster than their surrounding mid-tropospheric winds. 
TABLE 15

Radial band average of the relative (to the cyclone) component of the wind parallel to the direction of cyclone movement $\left(V_{P M}\right)$ at $5^{\circ}-7^{\circ}$ radius for northwest Pacific tropical cyclones. A negative value of $V_{P M}$ means the cyclone moves faster than the mean wind. Units: $m s^{-1}$.

STRATIFICATION $\quad \underline{700 \mathrm{mb}} \quad \underline{600 \mathrm{mb}} \quad \underline{500 \mathrm{mb}}$

By Latitude

North of $20^{\circ} \mathrm{N}$

$-1.4$

$-1.7$

$-0.5$

$-0.2$

South of $20 \% \mathrm{~N}$

$-1.5$

$-1.3$

By Speed

S1ow $\left(1-3 \mathrm{~m} \mathrm{~s}^{-1}\right),-0.9$

Moderate $\left(4-7\right.$ - $\left.\mathrm{s}^{-1}\right)$

Fast ( $7 \mathrm{~m} \mathrm{~s}^{-1}$ ) -2.4

$-0.3$

$-0.8$

$-0.9$

$-0.4$

$-0.8$

0.7

By Direction

Westward $\left(250^{\circ}-310^{\circ}\right), \quad-2.6$

Northward $\left(310^{\circ}-350^{\circ}\right) \quad-0.6$

$-1.3$

$-2.3$

$-2.3$

Eastward $\left(350^{\circ}-60^{\circ}\right)$

$-0.9$

$-1.3$

0.5

1.2

By Intensity

Weak (1000-980 mb)

Intense (950-980 mb)

$-1.4$

$-1.0$

$-0.3$

Very Intense (<950 mb)

$-1.4$

$-0.4$

$-0.3$

$-1.8$

$-2.0$

$-2.1$

By Intensity Change

Deepening North of $20^{\circ} \mathrm{N} \quad-0$.

Deepening South of $20^{\circ} \mathrm{N}-1.7$

-0.9
-1.7
-1.2

$-1.0$

$-1.5$

Filling North of $20^{\circ} \mathrm{N}$

$-1.2$

$-1.5$

$-1.5$

0.0

0.8

Filling South of $20^{\circ} \mathrm{N}$

$-2.4$

$-2.6$

By Size and Intensity

Sma11 Tropical Storm

Medium Tropical Storm

$-1.5$

$-1.0$

$-0.8$

$-1.2$

$-0.5$

$-0.1$

Large Tropical Storm

$-2.4$

$-1.9$

$-1.4$

Smal1 Typhoon

$-1.0$

$-0.6$

$-0.8$

Medium Typhoon

$-1.1$

$-0.2$

0.4

Large Typhoon

$-1.6$

$-0.7$

$-0.5$

Mean

$-1.5$

$-0.9$

$-0.5$

Scatter

0.5

0.8

1.2 
TABLE 16

Same as Table 15 except for west Atlantic tropical cyclones.

STRATIFICATION

$700 \mathrm{mb}$

$\underline{600 \mathrm{mb}}$

$\underline{500 \mathrm{mb}}$

By Latitude

Region I (South)

Region II (North)

By Speed

S1ow (1-3 m s $\left.\mathrm{s}_{-1}^{-1}\right)$

Fast ( $>3 \mathrm{~m} \mathrm{~s}^{-1}$ )

By Direction

Northward $\left(316^{\circ}-45^{\circ}\right)$

Westward $\left(225^{\circ}-315^{\circ}\right)$

By Intensity

Hurricane

Tropical Storm

By Size and Intensity

Sma11 Tropica1 Storm

Large Tropica1 Storm

Sma11 Hurricane

Large Hurricane North

Large Hurricane South

Mean

Scatter
$-0.6$

$-1.2$

$-0.6$

$-1.2$

$-1.0$

$-1.4$

$-0.6$

$-2.0$

$-0.6$

$-1.6$

$-0.5$

$-1.5$

$-1.7$

$-1.5$

$-1.4$

$-1.4$

$-0.8$

$-1.0$

$-1.0$

$-1.3$

$-1.0$

$-1.0$

$-1.3$

$-2.1$

$-1.5$

$-2.1$

$-1.0$

$-1.2$

$-1.7$

$-1.3$

$-1.5$

$-1.1$

$-1.3$

$-1.2$

0.5

0.4

0.4
$-1.3$

$-1.2$

$-1.4$

$-1.2$

$-0.8$

$-1.7$ 
TABLE 17

Same as Table 15 except for tropical cyclones in the Australian-south Pacific region.

STRATIFICATION $700 \mathrm{mb}$

$600 \mathrm{mb}$

$\underline{500 \mathrm{mb}}$

By Direction

Eastward $\left(40^{\circ}-150^{\circ}\right)$

$-3.1$

$-0.1$

$-0.9$

$-0.2$

2.0

Westward $\left(210^{\circ}-320^{\circ}\right)$

By Intensity and Region

\begin{tabular}{lllr} 
Hurricane & -1.6 & -0.9 & -0.2 \\
Coral Sea Hurricane & -2.6 & -1.3 & 0.8 \\
Cora1 Sea Tropica1 Storm & -2.1 & -1.6 & -0.6 \\
West Australian Hurricane & -0.2 & -2.0 & -2.1 \\
\hline & -1.6 & -1.2 & -0.3 \\
Mean & 1.2 & 0.6 & 1.5 \\
\hline
\end{tabular}

TABLE 18

Average $5^{\circ}-7^{\circ} \mathrm{V}_{\mathrm{PM}}$ for all data sets in each ocean basin and the cofresponding scatter at 700,600 and $500 \mathrm{mb}$ (in parentheses). Unit: m $s^{-1}$.

Ocean Basin

Northwest Pacific

West Atlantic

Australian-

south Pacific Region

\section{$700 \mathrm{mb}$}

$$
-1.5
$$

$(0.5)$

$-1.3$

$(0.5)$

$-1.6$

(1.2) $\underline{600 \mathrm{mb}}$

$-0.9$

$(0.8)$

$-1.2$

$(0.4)$

$-1.2$

$(0.6)$ $\underline{500 \mathrm{mb}}$

$-0.5$

(1.2)

$-1.3$

$(0.4)$

$-0.3$

(1.5) 
Summary. To compare results obtained from the different ocean basins, the mean values of $\bar{V}_{P M}$ for all data sets in a given ocean basin and the corresponding scatter are presented in Table 18 . One might conclude from this table that cyclones in both hemispheres move faster than the mid-tropospheric winds at $5-7^{\circ}$ by an average of $\sim 1 \mathrm{~m}$ $\mathrm{s}^{-1}$. Both 700 and $600 \mathrm{mb}$ appear to be better levels than $500 \mathrm{mb}$.

\section{(iii) Leve1- or 1ayer-averages}

To calculate the pressure-weighted averages of $\overline{\mathrm{V}}_{\mathrm{PM}}$, Eq. (2b) was used with $\bar{V}_{P M}$ in the integrand of the numerator instead of $\vec{V}_{P}$. Similarly, the $200 \mathrm{mb}$ and $900 \mathrm{mb}$ arithmetic average of $\overline{\mathrm{V}}_{\mathrm{PM}}$ can be computed using $\bar{v}_{P M}$ instead of $\vec{v}_{P}$ in Eq. (3b). Similar pressureweighted averages were calculated: surface to $100 \mathrm{mb}$, surface to 300 $\mathrm{mb}$, surface to $500 \mathrm{mb}$ and 700 to $500 \mathrm{mb}$.

Northwest Pacific. Table 19 shows the four pressure-weighted layer averages and the $200 \mathrm{mb}$ and $900 \mathrm{mb}$ average $\overrightarrow{\mathrm{V}}_{\mathrm{PM}}$ for a11 northwest Pacific cyclones. As with the layer-averaged directional deviations, not much variation exists among the different averages. This is also evident from the mean for all the data sets. Therefore, it appears that a relatively shallow layer would be nearly as representative of cyclone speed as a deep layer average. This is of course a reflection of the relatively small speed shear of the environmental wind.

The values of $200 \mathrm{mb}$ and $900 \mathrm{mb}$ average $\overline{\mathrm{V}}_{\mathrm{PM}}$ are also very consistent. This suggests that it may be possible to use the $200 \mathrm{mb}$ and $900 \mathrm{mb}$ winds to describe tropical cyclone movement in the northwest Pacific with some degree of confidence.

West Atlantic. The layer-averaged $5-7^{\circ} \overline{\mathrm{V}}_{\mathrm{PM}}$ values for west Atlantic tropical cyclones are shown in Table 20. The variation among 
TABLE 19

Leve1- and layer-averaged $5^{\circ}-7^{\circ} \mathrm{v}_{\mathrm{PM}}$ for different combination of levels for northwest Pacific tropical cyclones. See_fert for a description of how the averages were calculated. Unit: in $s^{-1}$.

Stratification

By Latitude

South of $20^{\circ} \mathrm{N}$

By Speed

Slow (1-3 m
Moderate (4-7
Fast ( $7 \mathrm{~m}$
By Direction

Westward $\left(250^{\circ}-310^{\circ}\right)$
Northward $\left(310^{\circ}-350^{\circ}\right)$

Eastward $\left(350^{\circ}-60^{\circ}\right)$

By Intensity

Weak (1000-980 mb)

Very Intense (<950 mb)
North of $20 \% \mathrm{~N}$

Intense (950-980 mb)

$$
\int_{\text {surface }}^{100 m b} \int_{\text {surface }}^{300 m b} \int_{\text {surface }}^{500 m b}
$$

$500 \mathrm{mb}$

$700 \mathrm{mb}$

$-0.6$

$-1.3$

$-1.0$

$-1.6$

$-1.7$

$-1.7$

$-0.6$

$-1.5$

$200 \mathrm{mb}+900 \mathrm{mb}$

Average

-0 .

$-1.1$

$-0.9$

$-0.9$

$-1.3$

$-0.6$

$-0.1$

$-1.1$

$-3.0$

$-0.9$

$-0.6$$$
-0.7
$$

$-1.1$

0.2

\section{$-2.2 \quad-2.3$}

$-1.0$

$-2.4$

$-0.8$

$-2.4$

$-0.9$

$-1.8$

0.2

$-1.7$

0.2

$-0.5$

$-0.8 \quad-1.1$

$-1.6$

$-0.9$

$-0.6$

$-2.0$

$-0.7$

$-1.9$

$-1.7$

$-1.4$

$-1.9$

$-0.5$

By Intensity Change

\begin{tabular}{lrrrrr} 
Deepening North of $20^{\circ} \mathrm{N}$ & -1.0 & -1.1 & -1.1 & -1.1 & -0.5 \\
Deepening South of $20^{\circ} \mathrm{N}$ & -1.5 & -1.7 & -1.7 & -1.5 & -1.1 \\
Filing North of $20^{\circ} \mathrm{N}$ & 0.2 & -0.7 & -1.9 & -0.1 & 0.8 \\
Fi11ing South of $20 \mathrm{~N}$ & -1.9 & -2.3 & -2.5 & -2.4 & -1.2 \\
& & & & & \\
By Size and Intensity & & & & & -1.5 \\
Sma11 Tropical Storm & -1.3 & -1.2 & -1.5 & -1.1 & -0.1 \\
Medium Tropical Storm & -0.2 & -0.7 & -1.4 & -0.6 & -1.5 \\
Large Tropica1 Storm & -1.7 & -1.9 & -2.3 & -1.9 & -1.4 \\
Sma11 Typhoon & -1.2 & -1.0 & -1.0 & -0.8 & -0.2 \\
Medium Typhoon & -0.1 & -0.4 & -1.0 & -0.3 & -0.3 \\
Large Typhoon & -0.7 & -1.0 & -1.7 & -1.0 & -0.7 \\
\hline & & & & & \\
Mean & -0.9 & -1.2 & -1.7 & -1.0 & 0.7 \\
\hline
\end{tabular}


TABLE 20

Same as Table 19 except for west Atlantic tropical cyclones.

Stratification

$\int_{\text {surface }}^{100 \mathrm{mb}} \int_{\text {surface }}^{300 \mathrm{mb}} \int_{\text {surface }}^{500 \mathrm{mb}} \int_{700 \mathrm{mb}}^{500 \mathrm{mb}}$ Average

By Latitude

Region I (South)

Region II (North)

By Speed
Slow (1-3 m $\left.\mathrm{s}^{-1}\right)$
Fast ( $\left.3 \mathrm{~m} \mathrm{~s}^{-1}\right)$

By Direction

Northward $\left(316^{\circ}-45^{\circ}\right)$

Westward $\left(225^{\circ}-315^{\circ}\right)$
Fast ( $3 \mathrm{~m} \mathrm{~s}^{-1}$ )

$-1.3$

$-1.4$

$-0.9$

$-1.3$

$-0.5$

$-1.7$

$-0.5$

$-1.8$

$-0.6$

$-2.2$

$-0.6$

$-1.7$

$-2.0$

By Intensity

Hurricane

Tropica1 Storm

By Size and Intensity

Sma11 Tropical Storm

Large Tropical Storm

Sma11 Hurricane

Large Hurricane North

Large Hurricane South

Mean

$-1.4$

$$
-1.6
$$

$-1.4$

$-2.0$

$-0.7$

$-1.5$

$-1.3$

$-0.8$

$-2.8$

$\begin{array}{rrrrr}1.3 & -1.2 & -1.1 & -1.1 & -1.4 \\ -1.6 & -1.3 & -1.1 & -1.1 & -1.7\end{array}$

\section{$-1.4$}

$-1.4$

$-1.3$

$-0.6$

$-1.7$

0.4

$$
-1.3
$$

$-1.8$

$-1.3$

$-1.3$

$-1.5$

$-1.3$

0.4

4

\begin{tabular}{rrr}
-1.4 & -1.2 & -1.2 \\
-2.3 & -1.7 & -0.6 \\
-1.5 & -1.4 & -1.0 \\
-2.2 & -1.5 & 0.2 \\
-1.2 & -1.3 & -1.5 \\
\hline-1.4 & -1.3 & -1.2 \\
0.6 & 0.3 & 0.8 \\
\hline
\end{tabular}

$-1.7$

$-1.2$

$-0.3$$$
.0
$$

Scatter

0.8 
different averages is also small for most data sets. The scatter among data sets is about the same for all four layer-averages.

The $200 \mathrm{mb}$ and $900 \mathrm{mb}$ average $\overline{\mathrm{V}}_{\mathrm{PM}}$ has a much 1arger scatter. This might restrict the use of this type of data for describing the cyclone speed more in the west Atlantic than in the northwest Pacific. Vertical wind shears in the west Atlantic are generally larger, probably due to the higher 1atitude of these storms.

Australian-south Pacific region. Table 21 shows the leve1- and layer-averaged $\bar{v}_{P M} 5-7^{\circ}$ for tropical cyclones in this region. As mentioned before, the vertical speed shear in this region is relatively large (see Fig. 15). Therefore, a large variation among different layer-averages exist for a given data set, as seen in Table 21 . Both the surface to $500 \mathrm{mb}$ and the $700 \mathrm{mb}$ to $500 \mathrm{mb}$ layer-averages give extreme1y good consistency. The deep layer averages have a larger spread. This is different than the layer-average directional deviations discussed in section 3 in which the mean tropospheric flow best describes the directional movement of a cyclone in this region. It appears from Fig. 15 that the speed shear is too variable among data sets to give a consistent $\vec{V}_{P M}$ when integrated over a deep 1 ayer. However, if the integration is through a shallower layer, the effect of the shear would not be felt as much.

Because of this large spread in vertical wind shear, the $200 \mathrm{mb}$ and 900 mb average $\bar{V}_{P M}$ has a wide scatter among data sets in this region. The possibility of using $200 \mathrm{mb}$ and $900 \mathrm{mb}$ information for cyclone steoring in the Australian-south Pacific region is thus more doubtful than in the northwest Pacific or the west Atlantic. 
TABLE 21

Same as Table 19 except for tropical cyclones in the Anstra1ian-south Pacific region.

Stratification

$$
\int_{\text {surface }}^{100 \mathrm{mb}} \int_{\text {surface }}^{300 \mathrm{mb}} \int_{\text {surface }}^{500 \mathrm{mb}} \int_{700 \mathrm{mb}}^{500 \mathrm{mb}} 200 \mathrm{mb}+900 \mathrm{mb}
$$

\section{By Direction}

Eastward $\left(40^{\circ}-150^{\circ}\right)$
Westward $\left(210^{\circ}-320^{\circ}\right)$

$\begin{array}{llll}0.2 & -0.8 & -2.5 & -0.5\end{array}$

1.0

$\begin{array}{llll}-2.2 & -1.9 & -1.5 & -0.6\end{array}$

$-3.3$

By Intensity and Region

\begin{tabular}{lllllr} 
Herricane & -0.7 & -1.3 & -2.1 & -0.8 & -0.4 \\
Coral Sea Hurricane & -0.8 & -1.5 & -2.4 & -0.9 & -0.7 \\
Coral Sea Tropica1 Storm & -2.4 & -2.1 & -2.4 & -1.4 & -2.4 \\
West Australian Hurricane & -0.1 & -1.0 & -1.7 & -1.5 & 1.0 \\
\hline Mean & -1.0 & -1.4 & -2.1 & -1.0 & -0.8 \\
Scatter & 1.1 & 0.5 & 0.4 & 0.4 & 1.8 \\
\hline
\end{tabular}

TABLE 22

Same as Table 18 except for leve1- or layer-averaged $V_{P M^{\circ}}$

Ocean Basin

$\int_{\text {surface }}^{100 m b} \int_{\text {surface }}^{300 m b} \int_{\text {surface }}^{500 m b} \int_{700 m b}^{500 m b} 200 m b+900 m b$

Northwest Pacific

$$
\begin{array}{lllll}
-0.9 & -1.2 & -1.7 & -1.0 & -0.7 \\
(0.7) & (0.5) & (0.6) & (0.7) & (0.7)
\end{array}
$$

West Atlantic

$$
\begin{array}{lllll}
-1.4 & -1.3 & -1.4 & -1.3 & -1.2 \\
(0.4) & (0.4) & (0.6) & (0.3) & (0.8)
\end{array}
$$

\begin{tabular}{llllll} 
Australian- & -1.0 & -1.4 & -2.1 & -1.0 & -0.8 \\
south Pacific Region & $(1.1)$ & $(0.5)$ & $(0.4)$ & $(0.4)$ & $(1.8)$ \\
\hline
\end{tabular}


Summary. Layer-averaged $\bar{V}_{P M}$ for all data sets in each of the three ocean basins is shown in Table 22 . It can be seen that in the three ocean basins, cyclones always move faster than the mean $5-7^{\circ}$ leve1- or 1ayer-averaged winds. The most consistent layer-average appears to be the surface to $300 \mathrm{mb}$ average. The mid-tropospheric average is also about the same between the three oceans. Therefore, it seems that what layer-average is the best depends very much on the vertical wind shear profile in the environment. The $200 \mathrm{mb}$ and $900 \mathrm{mb}$ average $\bar{v}_{P M}$ appears not to be nearly as useful as the mean layer information.

b. Individua1 Octants

As discussed in section 3 , radial band average winds are not typically available in individual storm situations. Therefore, one needs to find a sector of the radial band which gives similar consistency among a11 data sets. The scatter of $V_{P M}$ for all eight octants at $5-7^{\circ}$ were calculated at 700,600 and $500 \mathrm{mb}$. The average $V_{P M}$ between $200 \mathrm{mb}$ and $900 \mathrm{mb}$ is also calculated just to see if some of the octants may give better results than the belt average. The results for both the mid-tropospheric levels and the $200 \mathrm{mb}$ and $900 \mathrm{mb}$ average show in general a larger variation than the radial band average values. However, if the average between the two octants 1 (front) and 5 (rear) is taken, a consistency comparable to that of the radial band average is obtained.

Northrest Pacific. Table 23 shows that standard deviations for the different levels are almost the same, with the mean $200 \mathrm{mb}$ and $900 \mathrm{mb}$ $V_{P M}$ being the smallest. Therefore, it appears that at least in the northwest Pacific, the $200 \mathrm{mb}$ and $900 \mathrm{mb}$ wind in the front and rear 
Values of $V_{P M}$ in the northwest Pacific averaged between octant 1 (front) and octant $5^{M}$ (rear) in the $5-7^{\circ}$ radial band at various pressure levels.

\section{STRATIFICATION}

By Latitude

North of $20^{\circ} \mathrm{N}$

South of $20^{\circ} \mathrm{N}$

By Speed

S1ow $\left(1-3 \mathrm{~m} \mathrm{~s}^{-1}\right)$

Moderate $\left(4-7-\mathrm{p}^{-1}\right)$
Fast $\left(>7 \mathrm{~m} \mathrm{~s}^{-1}\right)$

$-1.4$

$-0.2$

$-0.8$
$-0.6$
0.2
0.3

$-1.5$

0.2

0.1
$-1.2$
0.3
1.4

$-0.5$

0.1

$-0.8$

Very Intense (< $950 \mathrm{mb}$ )

By Intensity Change

Deepening North of $20^{\circ} \mathrm{N}$

Deepening South of $20^{\circ} \mathrm{N}$

Filling North of $20^{\circ} \mathrm{N}$

Filiing South of $20 \% \mathrm{~N}$

By Size and Intensity

Sma11 Tropical Storm

Medium Tropical Storm

Large Tropical Storm

Sma11 Typhoon

Medium Typhoon

Large Typhoon

Mean

$-1.6$

$-0.9$

0.6

$-0.6$

0.4

0.7

$-0.7$

-1.2
-0.8
0.8
-0.8

$-3.1$

$-1.4$

0.6

$-1.0$

1.1

0.1

$-1.1$

$-0.1$

0.2

$-0.6$

$-0.6$

$-0.3$

$-0.2$

$-1.0$

$-0.6$

0.5

$-1.5$

$-0.3$

1.4

$-0.9$

$-0.3 \quad 0.2$

$-0.7 \quad 0.1$

$-1.6$

$-2.4$

1.5

$-0.7$

$-1.2$

$-0.5$

$-0.7$

$-0.1$

Scatter

0.8

0.8
$-0.3$

$-0.8$

$-0.1$

$-0.9$

$-0.7$

0.2

0.4

$-0.6$

$-0.9$

0.6 
TABLE 24

Same as Table 23 except for west Atlantic tropical cyclones.

STRATIFICATION

$700 \mathrm{mb}$

$600 \mathrm{mb}$

$500 \mathrm{mb}$

-

By Latitude

Region I (South)

Region II (North)

$0.2 \quad-0.7$

$-0.8$

$-1.1$

$-1.0$

$-1.4$

$-1.8$

$-0.1$

By Speed

S1ow (1-3 $\mathrm{ms}^{-1}$

Fast ( $3 \mathrm{~m} \mathrm{~s}^{-1}$ )

$-0.5$

$-1.3$

$-0.8$

$-1.0$

$-1.3$

$-0.4$

$-1.4$

-1.5
0.4

$-1.7$

$-0.5$

$-1.6$

$-1.4$

0.8

Northward $\left(316^{\circ}-45^{\circ}\right)$
Westward $\left(225^{\circ}-315^{\circ}\right)$

0.4

$-0.2$

$-0.5$

$-0.8$

$-2.1$

$-0.2$

Hurricane

Tropical Storm

By Size and Intensity

Sma11 Tropica1 Storm

Large Tropica1 Storm

Smal1 Hurricane

Large Hurricane North

Large Hurricane South

Mean

$-0.9$

$-1.1$

$-2.1$

$-0.8$

$-2.6$

$-0.4$

$-1.5$

$-1.9$

Scatter

0.9

$-1.3$

$-1.4$

$-1.2$

$-0.7$

$-1.0$

$-0.4$

$-1.7$

$-1.0$

$-1.4$

$-1.0$

$-1.3$

0.6

0.2

0.5

0.0

$-1.1$

$-0.4$

0.4

0.4

1.0 
octants wonld be as useful in describing cyclone speed as similar midtropospheric data.

West Atlantic. The octants 1 and 5 averaged $V_{P M}$ are shown in Table 24. The smallest scatter appears at $600 \mathrm{mb}$ and $500 \mathrm{mb}$. The $200 \mathrm{mb}$ and $900 \mathrm{mb}$ average appears less useful than in the northwest Pacific. Australian-south Pacific region. Octants 1 and 5 averaged $V_{P M}$ for Australian-south Pacific systems are given in Table 25. Much more variability exists at all the levels. Using winds at one or two octants to describe cyclone speed will probably not be satisfactory. The scatter among data sets for the $200 \mathrm{mb}$ and $900 \mathrm{mb}$ average $\mathrm{V}_{\mathrm{PM}}$ appears too large to be of much use.

Summary. Because of the difference in the environmental flow between cyclones in different ocean basins, the possibility of using winds at one or two octants to describe cyclone speed really depends on the vertical homogeneity of the flow. Individual octant information, in general, is not as useful as radial band average data in describing cyclone speed. 
TABLE 25

Same as Table 23 except for tropical cyclones in the Australian-south Pacific region.

STRATIFICATION

By Direction

Eastward $\left(40^{\circ}-150^{\circ}\right)$

Westward $\left(210^{\circ}-320^{\circ}\right)$

By Intensity and Region

Hurricane

Cora1 Sea Hurricane

Coral Sea Tropical Storm

West Australian Hurricane

Mean

Scatter
$700 \mathrm{mb}$

$600 \mathrm{mb}$

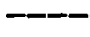

$-4.9$

$-0.6$

$-1.3$

1.6

$-2.2$

1.6

$-1.6$
$200 \mathrm{mb}+900 \mathrm{mb}$

Ave. 


\section{SUMMARY AND DISCUSSION}

The main conclusions of this study are:

a) the large-scale circulation is a key factor in determining the movement of tropical cyclones;

b) wind data at the mid-troposphere $(700,600$ and $500 \mathrm{mb})$ correlates best with both the direction and speed of cyclone movement;

c) on the average, tropical cyclones in the Northern Hemisphere moves $\sim 10^{\circ}-20^{\circ}$ to the left of the surrounding mid-tropospheric winds at $\sim 6^{\circ}$ radius from the cyclone center; an approximate opposite directional deviation occurs for cyclones in the Southern Hemisphere;

d) on the average, tropical cyclones move faster by $\sim 1 \mathrm{~m} \mathrm{~s}^{-1}$ than the surrounding mid-tropospheric winds at $\sim 6^{\circ}$ radius from the cyclone center;

e) cyclones having different zonal directions of cyclone motion have different relationships with their $5-7^{\circ}$ surrounding flow;

f) deep tropospheric flow appears to be a good descriptor of cyclone movement; for cyclones in a relatively weak shear environment a shallow layer-average flow is equally suitable; and

g) the average wind data between the upper (200 mb) and lower (900 mb) troposphere also correlate relatively well with the direction of movement and speed but less so than the wind data at the mid-troposphere or the mean layer data.

Some of these same conclusions were also made by George and Gray (1976), Gray (1977) and Brand et a1. (1981). Bell and Lam (1980) found that northwest Pacific tropical cyclones move, on the average, $0.9 \mathrm{~m} \mathrm{~s}^{-1}$ more northward and $3.4 \mathrm{~m} \mathrm{~s}^{-1}$ more westward compared to the geostrophic steering flow. This means that cyclones having a westward component of motion, which is normally the case, move faster than and to the left of the geostrophic flow, in qualitative agreement with the present study. From a forecasting point of view, these results imply that if one makes a forecast from a scheme based on steering flow, he would tend to 
predict the cyclone to move to the right of the actual track and slower than observed. This in fact was found to be the case by Kasahara (1957) using a barotropic non-divergent model. Since then, other numerical forecasts of tropical cyclone movement based on steering flow alone also produced a systematic rightward deflection of the predicted trajectory relative to the actual path and a predicted speed slower than the observed speed. See for example, Kasahara $(1959,1960)$, Birchfield (1960), Jones (1961, 1977), Sanders and Burpee (1968), Sanders et a1. (1975), Anthes and Hoke (1975), Harrison (1981), etc. Such systematic direction and speed biases have also been discussed by Neumann and Pelissier (1981) in the analyses of operational track forecast errors. Some of the authors have attributed such biased rightward deflection in the predicted track to the influence of the Coriolis acceleration as discussed by Rossby (1948). Birchfield (1961) managed to reduce the rightward bias in his model by implicitly including an interaction between the storm vortex and its surrounding flow. He gave no physical explanation, however. Kasahara and Platzman (1963) solved a modified barotropic potential-vorticity equation which included an interaction between the vortex and the steexing flow and obtained predicted directional tracks closer to the observed ones.

Theoretical studies by Rossby (1949), Adem (1956) and Kasahara and Platzman (1963) all suggest the importance of the zonal direction of cyclone motion in determining the relation between the environmental flow and cyclone movement. Their results imply a slight slow-down of vortex movement relative to the surrounding flow for eastward-moving cyclones while the opposite is true for westward- and northward-moving cyclones. The findings in this paper are consistent with these 
theoretical analyses. Recent studies by Holland (1982) and Chan (1982) also arrive at the same conclusion. They explained both the directional deviation and the difference in cyclone speed and environmental wind speed in texms of the variation of the Coriolis parameter across the cyclone.

Al1 these observational and theoretical results suggest that al though the environmental $\mathrm{flow}$ is important in the determination of cyclone motion, the steering flow theory cannot completely explain the physical processes involved in the movement of tropical cyclones. The interaction between the vortex and the environmental circulations must also be considered. 


\section{ACKNOWLEDGEMENTS}

The authors would like to thank Mr. Edwin Buzzell for his programming assistance and Mrs. Barbara Brumit and Ms. Cindy Schrandt for their help in manuscript preparation. Ne also thank Mr. Greg Holland, Dr. Geoff Love and Mr. Grant Burton for their help with the Australian/South Pacific data sets.

This research was supported by the Office of Nava1 Research Contract Grant No. N00014-C-0793. 


\section{REFERENCES}

Adem, J., 1956: A series solution for the barotropic vorticity equation and its application in the study of atmospheric vortices. Tellus. $8,364-371$.

Anthes, R. A, and J. A. Hoke, 1975: The effect of horizonta1 divergence and the latitudinal variation of the Coriolis parameter on the drift of a mode1 hurricane. Mon. Wea. Rev., 103, 757-763.

Be11, G. J. and c. Y. Lam, 1980: Departures of tropical cyclone movement from geostrophic steering. WMO Symp. on Typhoons, Shanghai, China, 0ct. 6-11, World Meteorological Organization, Geneva, Switzer1and, 110-115.

Birchfie1d, G. E., 1960: Numerical prediction of hurricane movement with the use of a fine grid. J. Meteor., 17, 406-414.

Birchfie1d, G. E., 1961: Numerical prediction of hurricane movement with the equivalent-barotropic mode1. I. Meteor., 18, 402-409.

Brand, S., C. A. Buenafe and H. D. Hamilton, 1981: Comparison of tropical cyclone motion and environmental steering. Mon. Hea. Rev.. $109,908-909$.

Chan, J. C. L., 1982: On the physical processes responsible for tropical cyclone motion. Ph.D. Thesis, Atmos. Sci. Dept., Colo. State Univ., Ft. Collins, Co, 80523.

Chan, J. C. L., W. M. Gray and S. Q. Kidder, 1980: Forecasting tropical cyclone turning motion from surrounding wind and temperature fie1ds. Mon. Wea. Rev., 108, 778-792.

Frank, W. M., 1977: The structure and energetics of the tropical cyclone, I: Storm structure. Mon. Wea. Rev., 105, 1119-1135.

George, J. E. and W. M. Gray, 1976: Tropical cyclone motion and surrounding parameter relationships. I. App1. Meteor., 15, 1252-1264.

Gray, W. M., 1977: Tropical cyclone motion and steering flow relationships in the western Atlantic and in the western Pacific. Preprints, 11th Tech. Conf. on Hurricanes and Tropical Meteorology, Dec. 13-16, Miami Beach, FL, 472-477.

Gray, W. M., 1981: Recent advances in tropical cyclone research from rawinsonde composite analysis. WMO Programme on Research in Tropical Meteorology. World Meteorological Organization, Geneve, Switzerland, 407 pp.

Harrison, E. J., Jr., 1981: Initial results from the Navy two-way interactive nosted tropical cyclone model. Mon. Wea. Rey., 109, 173-177. 
Holland, G. J., 1982: On tropical cyclone motion. To be submitted to Mon. Wea. Rev.

Jones, R. W., 1961: The tracking of hurricane Andrey, 1957 by numerical prediction. I. Meteor., 18, 127-138.

Jones, R. W., 1977: Vortex motion in a tropical cyclone mode1. J. Atmos. Sci., 34, 1518-1527.

Jordan, E. S., 1952: An observationa1 study of the upper wind circulation around tropical storms. I. Meteor., 9, 340-346.

Kasahara, A., 1957: The numerical prediction of hurricane movement with the barotropic mode1. I. Meteor., 14, 386-402.

Kasahara, A., 1959: A comparison between geostrophic and nongeostrophic numerical forecasts of hurricane movement with the barotropic steering mode1. J. Meteor., 16, 371-384.

Kasahara, A., 1960: The numerical prediction of hurricane movement with a two-leve1 baroc1inic mode1. J. Meteor., 17, 357-370.

Kasahara, A. and G. W. P1atzman, 1963: Interaction of a hurricane with the steering flow and its effect upon the hurricane trajectory. Te11us, 15, 321-335.

Miller, B. I., 1958: The use of mean layer winds as a hurricane steering mechanism. Nat'1 Hurricane Res. Proj. Rept., No. 18, 24 pp. (Available from Natinal Hurricane Research Lab., Coral Gables, FL.)

Miller, B. I. and P. L. Moore, 1960: A comparison of hurricane steering leve1s. Bu11. Amer. Meteor. Soc., 41, 59-63.

Neumann, C. J. and J. M. Pelissier, 1981: Mode1s for the prediction of tropical cyclone motion over the north Atlantic: An operational evaluation. Mon. Wea. Rev., 109, 522-538.

Renard, R. J., S. G. Colgan, M. J. Daley and S. K. Rinard, 1973: Forecasting th motion of North Atlantic tropical cyclones by the objective MOHATT scheme. Mon. Wea. Rev., 101, 206-214.

Rieh1, H, and R. J. Shafer, 1944: The recurvature of tropical storms. I. Meteor., 1, 42-54.

Rieh1, H. and N. H. Burgner, 1950: Further studies of the movement and formation of hurricanes and their forecasting. Bu11. Amer. Meteor. Soc. , 31, 244-253.

Rossby, C. G., 1948: On displacements and intensity change of atmospheric vortices. J. Marine Res., 7, 175-187.

Rossby, C. G., 1949: On a mechanism for the release of potential energy in the atmosphere. I. Meteor., 6, 163-180. 
Sanders, F. and R. H. Burpee, 1968: Experiments in barotropic hurricane track forecasting. J. App1. Meteor., 7, 313-323.

Sanders, F., A. C. Pike and J. P. Gaertner, 1975: A barotropic mode1 for operational prediction of tracks of tropical storms. I. Appl. Meteor.. 14, 265-280.

Tse, S. Y. W., 1966: A new method for the prediction of tyhoon movement using the 700 mb chart. Quart. J. Roy. Meteor. Soc.. 92, 239-254.

Williams, K. T. and W. M. Gray, 1973: Statistical analysis of satellite-observed trade wind cloud clusters in the western North Pacific. Te11us, 25, 313-336.

Wor1d Meteorological Organization, 1979: Operational techniques for forecasting tropical cyclone intensity and movement. WMO-528, Geneva, Switzer1and, 138 pp. 